\title{
APLICAÇÃO DA LÓGICA NEBULOSA NA PARAMETRIZAÇÃO DE UM NOVO ÍNDICE DE QUALIDADE DAS ÁGUAS
}

\author{
André Lermontov ${ }^{1}$ \\ Lídia Yokoyama ${ }^{2}$ \\ Mihail Lermontov ${ }^{3}$ \\ Maria Augusta Soares Machado ${ }^{4}$
}

Resumo: As metodologias que utilizam lógica nebulosa, uma das ferramentas da inteligência artificial, vêm cada vez mais sendo utilizadas no tratamento das incertezas e subjetividades intrínsecas dos problemas ambientais. Este estudo propõe a criação de um novo índice de qualidade das águas, o Índice Nebuloso de Qualidade das Águas (INQA), através de uma interface facilitadora, o sistema de inferência nebulosa. Compara-se então este novo índice aos já calculados pelas diversas metodologias existentes. Esta nova metodologia é validada utilizando-se as análises do monitoramento do rio Pardo, da região de Ribeirão Preto - SP, realizadas pela Companhia de Tecnologia de Saneamento Ambiental de São Paulo (CETESB) durante os anos de 2004 a 2006.

Palavras-chave: Lógica Nebulosa, Índice de Qualidade das Águas.

Abstract: Methodologies that use fuzzy logic, one of the artificial intelligence tools, is being increasingly used in the treatment of uncertainties and inherent subjectivities of environmental problems. This study proposes the creation of a new water quality index, the Fuzzy Water Quality Index (INQA) thru a facilitative interface, the fuzzy inference system. This new index is then compared to the ones already calculated by several existent methodologies. This new methodology is validated using the monitoring analysis of the Pardo river, Ribeirão Preto region, São Paulo, Brazil, disclosed by Companhia de Tecnologia de Saneamento Ambiental de São Paulo (CETESB) and carried out from 2004 to 2006 .

Keywords: Fuzzy Logic, Water Quality Index

\footnotetext{
${ }^{1}$ Tecnologia de Processos Químicos e Bioquímicos - DPI/EQ/UFRJ e-mail: lermontov.andre@gmail.com

${ }^{2} \mathrm{DPI} / \mathrm{EQ} / \mathrm{UFRJ}$ - e-mail: lídia@eq.ufrj.br

${ }^{3}$ GMA/IM/UFF - e-mail: mihail@vm.uff.br

${ }^{4}$ Faculdades IBMECRJ - e-mail: mmachado@ibmecrj.br
} 


\section{INTRODUÇÃO}

A avaliação da qualidade da água de rios nos países em desenvolvimento tem se tornado um problema nos últimos anos, especialmente devido à escassez progressiva deste recurso (Ongley, 1998).

Relatórios de qualidade de águas são normalmente voltados para um público técnico, apresentando dados de monitoramento com ênfase em parâmetros individuais, sem prover uma visão global da qualidade de um rio. As metodologias para integrar variáveis de qualidade de água em índices específicos, estão sendo cada vez mais requisitadas no cenário nacional e internacional. Vários autores integraram variáveis diversas de qualidade de água em índices únicos (Mitchell, 1996; Pesce e Wunderlin, 1999; Cude, 2001; Liou et al., 2004; Said et al., 2004; Silva e Jardim, 2006). A maioria destes índices teve como base o Índice de Qualidade de Água (IQA), desenvolvido pela U.S. National Sanitation Foundadtion (NSF, 2007).

A necessidade de técnicas mais apropriadas para gerenciar a importância das variáveis de qualidade da água, a interpretação dos limites aceitáveis para cada parâmetro e a metodologia utilizada para integrar parâmetros distintos envolvidos na avaliação dos processos é reconhecida. Neste sentido, algumas metodologias de integração da Inteligência Artificial na modelagem de qualidade da água emergiram (Chau, 2006). Através da lógica nebulosa, estas metodologias vêm sendo utilizadas no gerenciamento ambiental (Silvert, 1997, 2000).

Monitorar a qualidade da água e tomar decisões qualitativas com base em dados é um desafio para os engenheiros ambientais em cada etapa, desde a coleta da amostra, armazenamento, processamento até a análise e interpretação dos resultados. Cada uma das etapas envolvidas contém incertezas que se propagam ao longo de toda a cadeia.

Em virtude das limitações das modelagens determinísticas e aproximações via metodologias tradicionais do índice de qualidade das águas, um método mais avançado de indexação se faz necessário, capaz de contabilizar as informações imprecisas, vagas e nebulosas nas tomadas de decisões que envolvem a qualidade da água.

Este estudo tem como objetivo propor a criação de um novo Índice de Qualidade das Águas através de uma interface da Inteligência Artificial, baseada na Lógica Nebulosa e as ferramentas de Inferência Nebulosa, denominado Índice Nebuloso de Qualidade de Águas (INQA). Esta metodologia foi validada através de um estudo comparativo aos índices calculados através das diversas metodologias já propostas.

\section{DESENVOLVIMENTO}

\section{1 ÍNDICES DE QUALIDADE DAS ÁGUAS}

Um índice não objetiva descrever a variação de concentração de um poluente ou a alteração de um parâmetro separadamente. A dificuldade na elaboração de um Índice de Qualidade das Águas, IQA, está em sintetizar em um único número uma realidade complexa, onde inúmeras variáveis ambientais têm influência e a qualidade ser uma função indireta de seu uso proposto. Portanto, uma definição clara dos objetivos que se desejam alcançar com um índice se faz necessária. A elaboração de um de Índice de Qualidade das Águas pode ser simplificada ao levar em consideração somente as variáveis ambientais críticas que afetam determinado corpo hídrico.

As vantagens dos índices são a facilidade de comunicação com o público leigo, o status maior do que as variáveis isoladas e o fato de representar uma média de diversas variáveis em um único número, combinando unidades de medidas diferentes em uma única unidade.

Uma desvantagem no processo de indexação é que alguns parâmetros que constituem a equação do índice podem influenciar drasticamente no resultado final sem nenhuma justificativa científica. 
Horton (1965) desenvolveu, através de um estudo pioneiro, índices gerais, selecionando e ponderando parâmetros de qualidade de água diversos. Esta metodologia foi então aperfeiçoada pela U.S. National Sanitation Foundadtion (NSF, 2007).

A fórmula convencional e pioneira para se calcular um Índice de Qualidade das Águas se dá, matematicamente, através da média ponderada de alguns parâmetros pré-estabelecidos e normalizados numa escala entre 0 e 100 , multiplicados seus pesos relativos correspondentes disponíveis nas curvas de normalização e pesos relativos (NSF, 2007).

Conesa (1995) modificou a metodologia tradicional do cálculo do IQA e criou um outro índice, denominado Índice Subjetivo de Qualidade das Águas

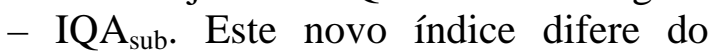
índice tradicional ao ter introduzido em sua formulação uma constante subjetiva denominada $k$. Esta constante assume valores entre 1 e 0,25 com intervalos de 0,25 , sendo o valor 1 representando uma água aparentemente sem contaminante e 0,25 uma amostra visualmente muito poluída (fortes odores e cores intensas). Os parâmetros que compõem esta formulação (eq. 1) devem ser previamente normalizados através das curvas de Conesa (1995) com os devidos pesos relativos. O Índice Objetivo de Qualidade das Águas - IQA $\mathrm{Ibj}_{\text {j }}$ resulta da eliminação desta constante $k$ subjetiva.

$$
\mathrm{IQA}_{\mathrm{sub}}=k \frac{\sum_{i} C_{i} \times P_{i}}{\sum_{i} P_{i}}
$$

Onde:

k é a constante subjetiva;

Ci é o valor de cada parâmetro após a normalização (Conesa, 1995);

Pi é o valor do peso relativo de cada parâmetro (Conesa, 1995).

O IQA utilizado no Brasil foi adaptado e desenvolvido pela CETESB, a partir do índice da NSF. O IQA incorpora 9 variáveis consideradas relevantes para a avaliação da qualidade das águas, tendo como determinante principal a sua utilização para abastecimento público de água potável.

A criação do IQA baseou-se numa pesquisa de opinião junto a especialistas em qualidade de águas, que indicaram as variáveis a serem avaliadas, o peso relativo e a condição com que se apresenta cada parâmetro, segundo uma escala de valores ponderados. Das 35 variáveis indicadoras de qualidade de água inicialmente propostas, somente 9 foram selecionadas. Para estas, a critério de cada profissional, foram estabelecidas curvas de variação da qualidade das águas de acordo com o estado ou a condição de cada parâmetro. Este conjunto de curvas de variação para cada parâmetro, bem como seu peso relativo correspondente, encontram-se disponíveis nos Relatórios de Qualidade das Águas Interiores do Estado de São Paulo (CETESB, 2004, 2005 e 2006).

O IQA é calculado através do produtório ponderado (eq. 2) da qualidade das águas normalizadas graficamente, correspondentes a nove variáveis, $n_{i}$ : Temperatura, $\mathrm{pH}$, Oxigênio Dissolvido, Demanda Bioquímica de Oxigênio $\quad\left(\mathrm{DBO}_{5}\right), \quad$ Coliformes Termotolerantes, Nitrogênio Total, Fósforo Total, Resíduo Total e Turbidez. Cada parâmetro é ponderado, $w_{i}$, por um valor variando entre 0 e 1 , cujo somatório iguala-se a 1 . O resultado é expresso em um valor numérico variando de 0 a 100 e divididos em 5 faixas de qualidades: [100 - 79) - Qualidade Ótima; [79 - 51) Qualidade Boa; [51 - 36) - Qualidade Média; [36 - 19) - Qualidade Ruim; [19 0] - Qualidade Péssima (CETESB, 2004, 2005 e 2006).

$$
\mathrm{IQA}=\prod_{i=1}^{n} \mathrm{q}_{i}^{w_{i}}
$$

Silva e Jardim (2006) desenvolveram mais um índice, denominado de Índice de Qualidade das Águas para a proteção da vida aquática (IQA $\left.{ }_{\mathrm{PVA}}\right)$, usando o conceito do operador mínimo. Este índice apresentou a vantagem de trabalhar com 
poucas variáveis ambientais. Isto causou a minimização de um clássico e indesejável efeito na elaboração de índices, o efeito eclipse. Este efeito é resultante da agregação de inúmeras variáveis ambientais em um único número, produzindo uma atenuação do impacto negativo de uma das variáveis frente ao comportamento estável das demais (Landwehr,1976; House, 1987).

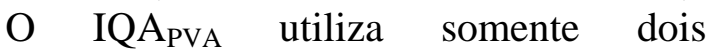
parâmetros, a amônia total (AT) e o oxigênio dissolvido (OD) conforme equação (eq. 3):

$$
\mathrm{IQA}_{\mathrm{PVA}}=\min \left(\mathrm{AT}_{\mathrm{n}}, \mathrm{OD}_{\mathrm{n}}\right) \quad \text { (eq. 3) }
$$

Um quarto índice, denominado de $\mathrm{IQA}_{\min }$, foi proposto por Pesce e Wunderlin (2000). O IQA min $_{\text {é calculado }}$ através da média aritmética dos valores normalizados (eq. 4) pelas curvas de Conesa (Conesa, 1995) de três parâmetros ambientais: Oxigênio Dissolvido (OD), Turbidez (Turb) e Fósforo Total (FT).

$$
\mathrm{IQA}_{\min }=\frac{\mathrm{OD}+\mathrm{Turb}+\mathrm{FT}}{3}
$$

$\mathrm{Na}$ literatura, outras metodologias de cálculo de índices são encontradas. Bordalo et al. (2001) modificou a equação do Índice de Qualidade das Águas Escocês (SDD,1976) e adaptou esta à rios tropicais, usando esta nova equação para indexar um rio na Tailândia. Stambuk Giljanovic (1999) apresentou um índice de avaliação das águas. Diferentemente de outros índices, este integra em sua fórmula parâmetros físico-químicos e coeficientes de mineralização e corrosão. Estes índices não serão discutidos neste estudo.

\subsection{INFERÊNCIA NEBULOSA}

Os sistemas baseados em conhecimento ou sistemas especialistas são alguns dos campos da Inteligência Artificial (IA). A essência destes sistemas é a aquisição de uma base de conhecimento heurístico, geralmente representada através de um conjunto de expressões condicionais qualitativas e com significado verbal, cujo mérito é ser semanticamente claro. Esses sistemas são capazes de ampliar sua base de conhecimento definida inicialmente, através de um processo de inferência ou “aprendizado” e são, por isso, às vezes, chamados de sistemas inteligentes.

Um dos segmentos de pesquisa da IA é a denominada Lógica Nebulosa. Foi concebida inicialmente como uma forma para representar um conhecimento inerentemente vago ou de natureza lingüística. Sua base é constituída pela matemática dos conjuntos nebulosos, a qual foi concebida para tratar das incertezas através de uma abordagem alternativa (ZADEH, 1965).

A inferência nebulosa é o resultado do casamento da lógica nebulosa com os sistemas baseados em conhecimento (Yager, 1994). Os modelos mais comuns utilizados para representar o processo de classificação de corpos hídricos se denominam de modelos determinísticos conceituais. Determinísticos, porque ignoram as propriedades estocásticas inerentes ao processo; e conceituais, porque buscam uma interpretação física para os diversos sub-processos envolvidos. Esses modelos utilizam, muitas vezes, uma grande quantidade de parâmetros, o que torna a sua modelagem uma tarefa bastante complexa.

Os modelos baseados em regras nebulosas têm-se apresentado como instrumentos adequados para representar incertezas e imprecisões de conhecimento e de dados. Esses modelos podem representar aspectos qualitativos do conhecimento e dos processos de inferência humana, sem empregar análise quantitativa precisa. São, portanto, menos precisos do que os modelos numéricos convencionais. Entretanto, o ganho em simplicidade, velocidade computacional e flexibilidade que resultam do uso desses modelos, podem compensar uma possível perda de precisão (Bárdossy, 1995).

Há, ainda, pelo menos três razões pelas quais a abordagem baseada em regras nebulosas podem ser justificadas (Bárdossy, 1995): primeiro, o fato de que uma ampla variedade de relações não 
lineares pode ser descrita; segundo, o fato desses modelos serem simples, porque cada modelo é composto de um conjunto de modelos locais simples; e terceiro, o fato deles serem verbalmente interpretáveis, o que lhes dá uma característica próxima aos modelos de IA.

$\mathrm{O}$ sucesso com o qual os sistemas baseados em regras nebulosas têm sido utilizados para modelar sistemas dinâmicos em outros campos da ciência e da engenharia sugere que esta abordagem possa mostrar-se um efetivo e eficiente caminho para modelar a criação de um IQA, principalmente, quando o conhecimento explícito dos subprocessos internos do processo de indexação não é requerido.

A lógica nebulosa estende a lógica tradicional com a introdução do conceito da verdade parcial, permitindo uma pertinência simultânea e parcial em vários conjuntos ao invés de uma inclusão total em um conjunto definido Ross (2004).

Duas razões motivaram o desenvolvimento da lógica nebulosa. Primeiro, a lógica nebulosa aponta para um alívio nas dificuldades do desenvolvimento e análise de sistemas complexos encontrados nas ferramentas matemáticas convencionais. Segundo, é motivada pela observação do raciocínio humano em utilizar conceitos e conhecimentos desprovidos de fronteiras bem definidas como, por exemplo, conceitos vagos. A primeira motivação está diretamente relacionada com a solução dos problemas do mundo real, enquanto a segunda está relacionada com a Inteligência Artificial. A conjunção destas motivações não só torna a lógica nebulosa única e diferente de outras metodologias, como forma uma ponte natural entre o mundo quantitativo e o qualitativo. Esta tecnologia oferece um grande benefício único, não só provê meios com ótimo custo-benefício de modelar um complexo sistema envolvendo variáveis numéricas, como também oferece uma descrição qualitativa do sistema que é de fácil compreensão
A inferência nebulosa é o processo que formula o mapeamento de um dado conjunto de entrada a um conjunto de saída usando a lógica nebulosa. Este mapeamento provê base para tomadas de decisões ou discernimento de padrões. $\mathrm{O}$ processo de inferência nebulosa envolve quatro etapas importantes: 1) conjuntos nebulosos e funções de pertinência; 2) operações com conjuntos nebulosos; 3) lógica nebulosa; e 4) regras de inferência. Um aprofundamento destes conceitos pode ser encontrado em Bárdossy (1995), Yen e Langari (1999), Ross (2004), Cruz (2004) e Caldeira (2007)

A teoria dos conjuntos nebulosos vem sendo cada dia mais desenvolvida, a fim de mapear as interpretações lingüísticas e incertezas dos fenômenos ambientais (Silvert, 1997, 2000). Algumas metodologias que fazem uso do sistema inferência nebulosa foram testadas em situações reais de gestão, monitoramento e problemas ambientais.

O conceito da teoria dos conjuntos nebulosos foi descrito por Chau (2006) como sendo útil na modelagem da qualidade das águas, uma vez que lida com uma aproximação alternativa em torno dos problemas em que os objetivos e fronteiras não estão bem definidos ou são imprecisos.

Ocampo-Duque et al. (2006) descreveram simples e profundamente a teoria em torno dos sistemas de inferência nebulosa. Utilizou a ferramenta da inferência nebulosa para indexar 27 parâmetros de monitoramento de um rio. Após normalizar todos os parâmetros e agrupaá-los em 5 grupos de parâmetros afins, estes foram nebulizados em 3 conjuntos. O resultado após a inferência foi a criação de um índice nebuloso de qualidade da água. Icaga (2007) aplicou a inferência nebulosa em qualidade de rios para enquadrá-los em suas classes de uso. Dahiya et al. (2007) aplicaram a teoria dos conjuntos nebulosos na avaliação dos parâmetros físico-químicos de águas subterrâneas para fins da determinação da sua potabilidade. 


\section{3}

\section{O RIO PARDO}

$\mathrm{O}$ rio Pardo nasce de uma pequena mina, de águas límpidas, na Serra do Cervo, nos contrafortes da Serra da Mantiqueira, no estado de Minas Gerais. Atravessa a região noroeste do estado de São Paulo e, após percorrer $240 \mathrm{~km}$ com uma bacia de drenagem de $8.993 \mathrm{~km}^{2}$ (Figura 1), deságua na foz do Rio Mogi-Guaçu. Este estudo se restringe a área de abrangência da quarta Unidade de Gerenciamento de Recursos Hídricos (UGRHI 4),dentro da bacia do rio Pardo, da Companhia de Tecnologia de Saneamento Ambiental (CETESB), ligada a Secretaria de Estado do Meio Ambiente do Estado de São Paulo. Os principais usos do solo dentro desta área são urbano-industrial e agrícola, com presença de culturas de cana de açúcar (329.924 hectares), pastagens (261.999 hectares), fruticultura (83.611 hectares) e silvicultura (46640 hectares). Cerca de 3\% da população do estado vivem nesta UGRHI (1.056.658 pessoas) com $97 \%$ de população predominantemente urbana, espalhadas por 23 cidades. Os principais usos da água são para abastecimento público e industrial, afastamento de efluentes e irrigação de plantações. Cerca de 99\% dos efluentes são coletados e $51 \%$ são tratados. Estima-se que aproximadamente 31 toneladas de DBO (carga poluidora remanescente) são lançadas nos corpos receptores para afastamento dentro desta bacia hidrográfica (CETESB, 2006).

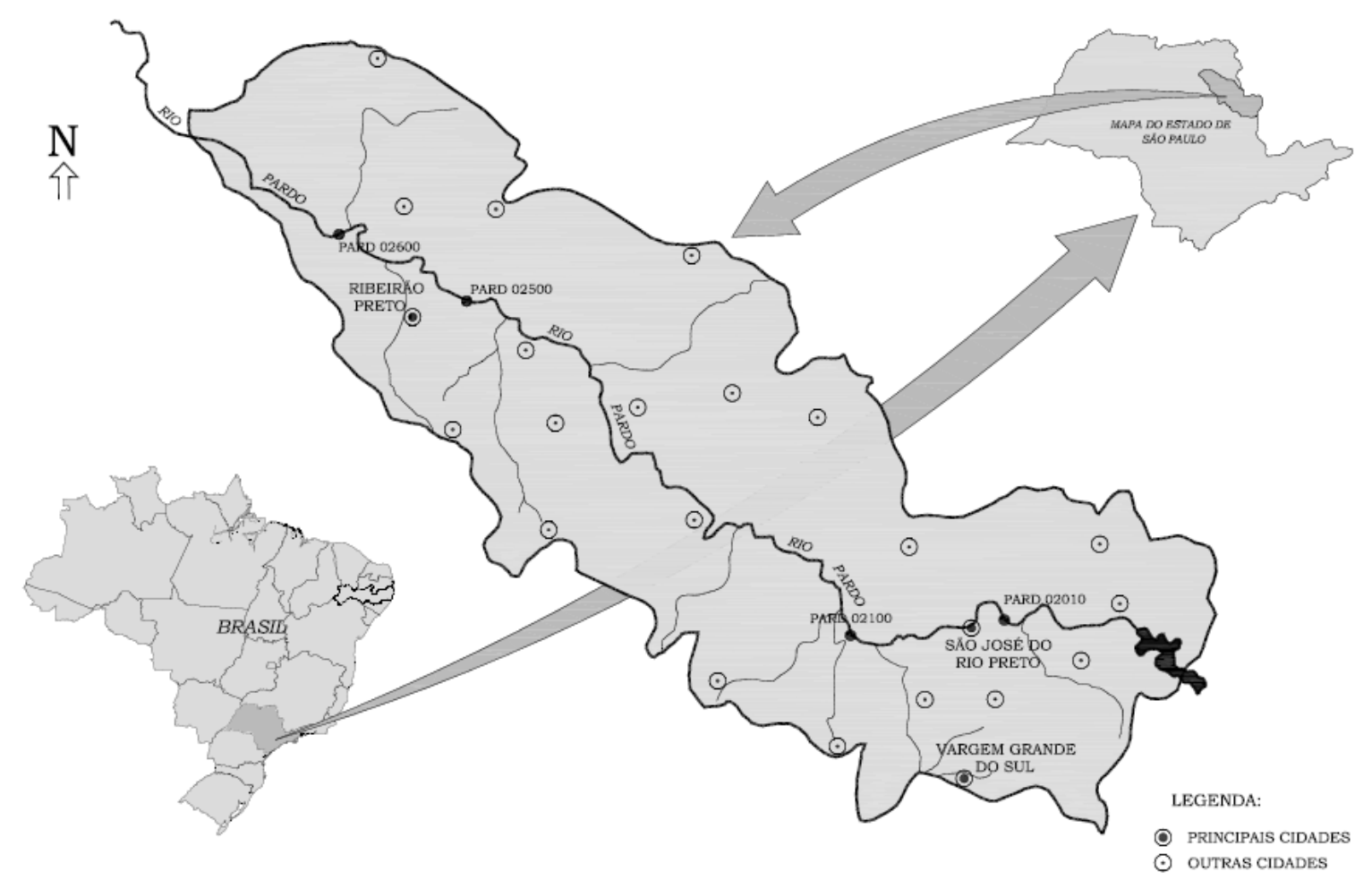

Figura 1 - Localização geográfica da bacia do rio Pardo.

Os dados para este estudo foram retirados dos "Relatórios de Qualidade das Águas Interiores do Estado de São Paulo", publicados pela CETESB, referentes aos anos de 2004 a 2006. Utilizou-se a mesma codificação dos relatórios (Figura 1): ponto P1, código PARD02010, localizado sob a ponte na rodovia SP-350, no trecho que liga São José do Rio Pardo à Guaxupéque; ponto P2, código PARD02100, sob a Ponte na rodovia SP-340, trecho que liga Casa Branca a Mococa; ponto P3, código PARD02500, na margem esquerda, no Clube de Regatas de Ribeirão Preto. O último ponto, P4, código PARD0260, situa-se à margem direita, a $50 \mathrm{~m}$ da ponte da rodovia que liga Pontal a Cândia e é praticamente o último ponto no final da bacia. 


\section{DAS ÁGUAS}

O desenvolvimento do Índice Nebuloso de Qualidade das Águas (INQA) não é uma tarefa fácil. Integrar a lógica nebulosa e o sistema de inferência nebuloso às variáveis de monitoramento ambiental sem prejudicar o resultado final requer uma mudança de conceito.

Nas metodologias tradicionais de cálculo do IQA, os parâmetros são normalizados através de tabelas ou curvas próprias (Conesa, 1995; Pesce e Wunderlin, 1999; CETESB, 2004, 2005 e 2006; NSF, 2007) e em seguida calculados por métodos matemáticos convencionais. Nesta metodologia os parâmetros foram normalizados e agrupados através de um sistema de inferência nebulosa.

Para este estudo foram utilizados os nove parâmetros que compõem o IQA utilizados pela CETESB: temperatura (Temp), $\mathrm{pH}(\mathrm{pH})$, oxigênio dissolvido (OD), demanda bioquímica de oxigênio (DBO), coliformes termotolerantes (Coli), nitrogênio total (NT), fósforo total (FT), resíduo total (ST) e turbidez (Turb). A equipe envolvida neste trabalho ainda estuda o desenvolvendo de um índice com a inclusão de outros parâmetros, como metais pesados e compostos tóxicos, para uma indexação mais realista dos corpos hídricos.

Os conjuntos nebulosos foram definidos nos termos de uma função de pertinência que mapeiam um domínio de interesse num intervalo $[0,1]$.

Os formatos das curvas mapeiam a função de pertinência em cada conjunto e estas mostram o grau em que um valor específico pertence ao respectivo conjunto (eq. 5):

$\mu \mathrm{A}: \mathrm{X} \rightarrow[0,1]$

O conjunto A pode ainda ser definido nos termos de sua função de pertinência: $\mu A=\left\{\begin{array}{ll}=1 & \text { x é membro integral de } A \\ (0,1) & \text { x é membro parcial de } A \\ =0 & \text { x não é membro de } A\end{array}\right\}$
Foram criadas funções de pertinência trapezoidais e triangulares para os nove parâmetros (Tabela 1 e Tabela 2) conforme equações abaixo:

Trapezoidais:

$$
f(x ; a, b, c, d)=\left\{\begin{array}{ll}
0 & \text { se } x<a \text { e } d<x \\
\frac{(\mathrm{a}-\mathrm{x})}{(\mathrm{a}-\mathrm{b})} & a \leq x \leq b \\
1 & b \leq x \leq c \\
\frac{(\mathrm{d}-\mathrm{x})}{(\mathrm{d}-\mathrm{c})} & c \leq x \leq d
\end{array}\right\}
$$

A função de pertinência trapezoidal tem a forma da Figura 2.

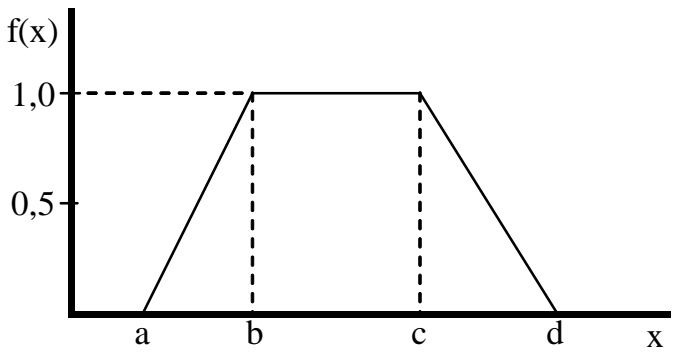

Figura 2 - Função de pertinência trapezoidal

Triangulares:

$$
f(x ; a, b, c)=\left\{\begin{array}{ll}
0 & \text { se } x<a \text { e c }<x \\
\frac{(\mathrm{a}-\mathrm{x})}{(\mathrm{a}-\mathrm{b})} & a \leq x \leq b \\
\frac{(\mathrm{c}-\mathrm{x})}{(\mathrm{c}-\mathrm{b})} & b \leq x \leq c
\end{array}\right\}
$$

A função de pertinência triangular tem a forma da Figura 3.

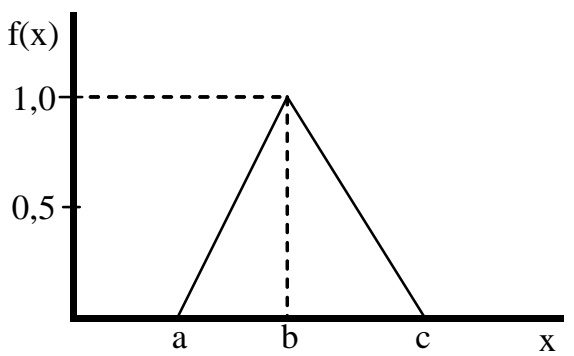

Figura 3 - Função de pertinência triangular 
Em um sistema nebuloso baseado em regras a cada conjunto é atribuída uma descrição lingüística. Os conjuntos são então nomeados conforme um grau perceptível de qualidade variando estes desde Muito Ótimo, Ótimo, Muito Bom até Muito Péssimo (Tabelas 1, 2, 3, 4, 5 e 6). Este estudo utilizou o modelo lingüístico de inferência nebulosa onde os conjuntos de entrada, as variáveis de qualidade de água, chamadas de antecedentes, foram processadas através de um conjunto de regras lingüísticas do tipo se / então, tendo como resultado um conjunto de saída, os grupos, denominados de conseqüentes.

Tabela 01 - Conjuntos Nebulosos e termos lingüísticos do Grupo 01.

\begin{tabular}{|c|c|c|c|c|c|c|c|c|}
\hline & & & & & 01 & & & \\
\hline Parâmetro & & Tem & atura & & & $\mathrm{p}$ & & \\
\hline Simbolo & & & & & & $\mathrm{pl}$ & & \\
\hline Unidade & & & & & & & & \\
\hline Intervalo & & & & & & $1-$ & 14 & \\
\hline Variável lingustíca & $\mathrm{a}$ & $\mathrm{b}$ & C & $d$ & $\mathrm{a}$ & $\mathrm{b}$ & C & d \\
\hline Muito Otimo - MO & 15 & 16 & 21 & 22 & 6.80 & 6.90 & 7.10 & 7.75 \\
\hline Otimo - O & 14 & 15 & 16 & & 7.10 & 7.75 & 8.25 & \\
\hline & 21 & 22 & 24 & & 6.60 & 6.80 & 6.90 & \\
\hline Muito Bom - MB & 13 & 14 & 15 & & 7.75 & 8.25 & 8.50 & \\
\hline & 22 & 24 & 26 & & 6.30 & 6.60 & 6.80 & \\
\hline Bom - B & 10 & 13 & 14 & & 8.25 & 8.50 & 8.75 & \\
\hline & 24 & 26 & 28 & & 6.10 & 6.30 & 6.60 & \\
\hline Médio/Bom - MedB & 5 & 10 & 13 & & 8.50 & 8.75 & 9.00 & \\
\hline & 26 & 28 & 30 & & 5.85 & 6.10 & 6.30 & \\
\hline Médio - Med & 0 & 5 & 10 & & 8.75 & 9.00 & 9.20 & \\
\hline & 28 & 30 & 32 & & 5.60 & 5.85 & 6.10 & \\
\hline Médio/Ruím - MedR & -2 & 0 & 5 & & 9.00 & 9.20 & 9.60 & \\
\hline & 30 & 32 & 36 & & 5.20 & 5.60 & 5.85 & \\
\hline Ruím - R & -4 & -2 & 0 & & 9.20 & 9.60 & 10.00 & \\
\hline & 32 & 36 & 40 & & 4.75 & 5.20 & 5.60 & \\
\hline Muito Ruim - MR & -6 & -4 & -2 & & 9.60 & 10.00 & 10.50 & \\
\hline & 36 & 40 & 45 & & 4.00 & 4.75 & 5.20 & \\
\hline Péssimo - $P$ & -6 & -6 & -4 & & 10.00 & 10.50 & 12.00 & \\
\hline & 40 & 45 & 45 & & 2.00 & 4.00 & 4.75 & \\
\hline Muito Péssimo - MP & -6 & -6 & -6 & & 10.50 & 14.00 & 14.00 & \\
\hline & 45 & 45 & 45 & & 1.00 & 1.00 & 4.00 & \\
\hline
\end{tabular}

Tabela 02 - Conjuntos Nebulosos e termos lingüísticos do Grupo 02.

\begin{tabular}{|c|c|c|c|c|c|c|c|c|}
\hline & \multicolumn{8}{|c|}{ GrO2 } \\
\hline Parâmetro & \multicolumn{4}{|c|}{ Oxigênio Dissolvido } & \multicolumn{4}{|c|}{$\begin{array}{l}\text { Demanda Bioqímica } \\
\text { de Oxogênio }\end{array}$} \\
\hline Simbolo & \multicolumn{4}{|c|}{ OD } & \multicolumn{4}{|c|}{ DBO } \\
\hline Unidade & \multicolumn{4}{|c|}{$\mathrm{mg} / \mathrm{l}$} & \multicolumn{4}{|c|}{$\mathrm{mg} / \mathrm{l}$} \\
\hline Intervalo & \multicolumn{4}{|c|}{$0-9$} & \multicolumn{4}{|c|}{$0-30$} \\
\hline Variávellingustíca & $\bar{a}$ & $\mathrm{~b}$ & $\mathrm{C}$ & $\mathrm{d}$ & $\bar{a}$ & $\mathrm{~b}$ & $\mathrm{C}$ & $\mathrm{d}$ \\
\hline Muito Otimo - MO & 7.0 & 7.5 & 9.0 & 9.0 & 0 & 0 & 0.5 & 2 \\
\hline Otimo - O & 6.5 & 7 & 7.5 & & 0.5 & 2 & 3 & \\
\hline Muito Bom - MB & 6 & 6.5 & 7 & & 2 & 3 & 4 & \\
\hline Bom - B & 5 & 6 & 6.5 & & 3 & 4 & 5 & \\
\hline Médio/Bom - MedB & 4 & 5 & 6 & & 4 & 5 & 6 & \\
\hline Médio - Med & 3.5 & 4 & 5 & & 5 & 6 & 8 & \\
\hline Médio/Ruím - MedR & 3 & 3.5 & 4 & & 6 & 8 & 12 & \\
\hline Ruím - R & 2 & 3 & 3.5 & & 8 & 12 & 15 & \\
\hline Muito Ruim - MR & 1 & 2 & 3 & & 12 & 15 & 22 & \\
\hline Péssimo - P & 0 & 1 & 2 & & 15 & 22 & 30 & \\
\hline Muito Péssimo - MP & 0 & 0 & 1 & & 22 & 30 & 30 & \\
\hline
\end{tabular}


Tabela 03 - Conjuntos Nebulosos e termos lingüísticos do Grupo 03

\begin{tabular}{|c|c|c|c|c|}
\hline & \multicolumn{4}{|c|}{ Gr03 } \\
\hline Parâmetro & \multicolumn{4}{|c|}{ Coliformes Termotolerantes } \\
\hline Simbolo & \multicolumn{4}{|c|}{ Coli } \\
\hline Unidade & \multicolumn{4}{|c|}{$\mathrm{mg} / \mathrm{l}$} \\
\hline Intervalo & \multicolumn{4}{|c|}{$0-18.000$} \\
\hline Variávellingustíca & $\bar{a}$ & $\mathrm{~b}$ & $\mathrm{C}$ & d \\
\hline Muito Otimo - MO & 0 & 0 & 1 & 1 \\
\hline Otimo - O & 1 & 2 & 3 & \\
\hline Muito Bom - MB & 2 & 3 & 8 & \\
\hline Bom - B & 3 & 8 & 16 & \\
\hline Médio/Bom - MedB & 8 & 16 & 40 & \\
\hline Médio - Med & 16 & 40 & 100 & \\
\hline Médio/Ruím - MedR & 40 & 100 & 300 & \\
\hline Ruím - R & 100 & 300 & 1000 & \\
\hline Muito Ruim - MR & 300 & 1000 & 6000 & \\
\hline Péssimo - P & 1000 & 6000 & 18000 & \\
\hline Muito Péssimo - MP & 6000 & 18000 & 18000 & \\
\hline
\end{tabular}

Tabela 04 - Conjuntos Nebulosos e termos lingüísticos do Grupo 04

qualidade são processadas por sistemas de inferência e tendo como resultado os seus respectivos grupos normalizados entre 0 e 100. Os grupos são então novamente processados através de uma nova inferência, tendo como resultado final, o Î́ndice Nebuloso de Qualidade das Águas - INQA.

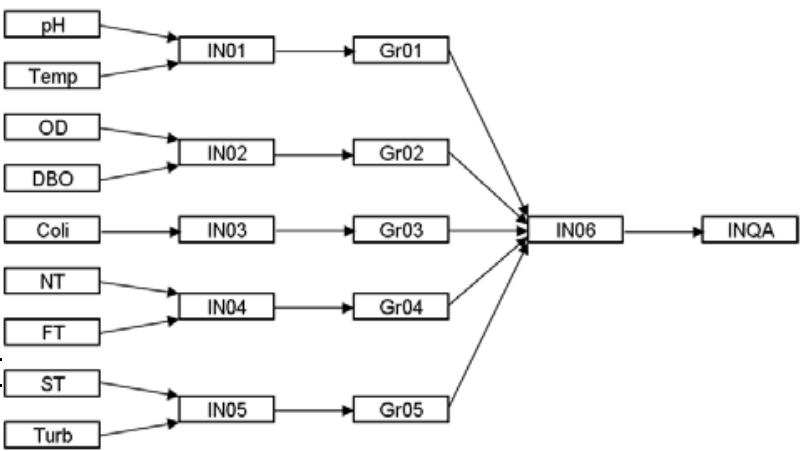

Figura 04 - Fluxograma de processamento

O primeiro grupo (Gr01) normalizou e agregou os parâmetros físicos $\mathrm{pH}$ e Temp. O segundo (Gr02) o OD e a DBO. Os coliformes termotolerantes, grupo microbiológico, foram normalizados independentemente (Gr03). $\mathrm{O}$ quarto grupo (Gr04) englobou os nutrientes como o NT e FT e o quinto (Gr05) agregou e normalizou os ST e a Turb. Os resultados das análises de água da Tabela 05 - Conjuntos Nebulosos e termos lingüísticos do Grupo 05

\begin{tabular}{|c|c|c|c|c|c|c|c|c|}
\hline & \multicolumn{8}{|c|}{$\frac{1}{\text { Gr05 }}$} \\
\hline \multirow{5}{*}{$\begin{array}{l}\text { Parâmetro } \\
\text { Simbolo } \\
\text { Unidade } \\
\text { Intervalo } \\
\text { Variáyelningustica }\end{array}$} & \multirow{4}{*}{\multicolumn{4}{|c|}{$\begin{array}{c}\text { Sólidos Totais } \\
\text { ST } \\
\text { mg/l } \\
0-750\end{array}$}} & \multirow{4}{*}{\multicolumn{4}{|c|}{$\begin{array}{c}\text { Turbidez } \\
\text { Turb } \\
\text { mg/l } \\
0-150\end{array}$}} \\
\hline & & & & & & & & \\
\hline & & & & & & & & \\
\hline & & & & & & & & \\
\hline & $\bar{a}$ & b & $\bar{C}$ & d & $\bar{a}$ & $\mathrm{~b}$ & $\bar{C}$ & d \\
\hline Muito Otimo - MO & 0 & 0 & 5 & 50 & 0 & 0.0 & 0.5 & 2.5 \\
\hline Otimo - O & 0 & 50 & 150 & & 0.5 & 2.5 & 7.5 & \\
\hline Muito Bom - MB & 50 & 150 & 250 & & 2.5 & 7.5 & 12.5 & \\
\hline Bom - B & 150 & 250 & 320 & & 7.5 & 12.5 & 22.5 & \\
\hline Médio/Bom - MedB & 250 & 320 & 400 & & 12.5 & 22.5 & 35 & \\
\hline Médio - Med & 320 & 400 & 450 & & 22.5 & 35 & 50 & \\
\hline Médio/Ruím - MedR & 400 & 450 & 550 & & 35 & 50 & 70 & \\
\hline Ruím - R & 450 & 550 & 600 & & 50 & 70 & 95 & \\
\hline Muito Ruim - MR & 550 & 600 & 650 & & 70 & 95 & 120 & \\
\hline Péssimo - P & 600 & 650 & 750 & & 95 & 120 & 150 & \\
\hline Muito Péssimo - MP & 650 & 750 & 750 & & 120 & 150 & 150 & \\
\hline
\end{tabular}

Tabela 06 - Conjuntos Nebulosos e termos lingüísticos do conseqüente

\begin{tabular}{lcccc}
\hline & \multicolumn{4}{c}{ Grupo de Saida } \\
\hline Intervalo & \multicolumn{4}{c}{ - 100} \\
Variável lingustíca & $\mathrm{a}$ & $\mathrm{b}$ & $\mathrm{c}$ & $\mathrm{d}$ \\
\hline Muito Otimo - MO & 0 & 0 & 1 & 10 \\
Otimo - O & 0 & 10 & 20 & \\
Muito Bom - MB & 10 & 20 & 30 & \\
Bom - B & 20 & 30 & 40 & \\
Médio/Bom - MedB & 30 & 40 & 50 & \\
Médio - Med & 40 & 50 & 60 & \\
Médio/Ruím - MedR & 50 & 60 & 70 & \\
Ruím - R & 60 & 70 & 80 \\
Muito Ruim - MR & 70 & 80 & 90 & \\
Péssimo - P & 80 & 90 & 100 \\
Muito Péssimo - MP & 90 & 100 & 100 \\
\hline
\end{tabular}

A Figura 4 mostra o fluxograma de processo onde as variáveis individuais de UGRHI utilizados neste estudo foram extraídos dos Relatórios de Qualidade das Águas Interiores do Estado de São Paulo, Brasil, referentes aos anos de 2004, 2005 e 2006. Como base para criação e normalização dos conjuntos nebulosos deste estudo foram utilizadas as curvas da CETESB para os parâmetros $\mathrm{pH}$, DBO, Coli, NT, FT, ST e Turb e as curvas de Conesa para Temp e OD.

As regras para normalização e agrupamento seguiram a lógica descrita a seguir e o conseqüente obedeceu sempre à imposição do operador mínimo:

Se PP é MO e SP é MO então saída do GR é MO

Se PP é MO e SP é O então saída do Grupo é O

Se PP é O e SP é MO então saída do Grupo é O

\section{...}

ENGEVISTA, v. 10, n. 2, p. 106-125 dezembro 2008 
Se PP é MO e SP é MP então saída do Grupo é MP

Se PP é MP e SP é MO então saída do Grupo é MP

PP - Primeiro Parâmetro;

SP - Segundo Parâmetro ;

GR - Grupo.

O INQA foi desenvolvido a partir de uma inferência nebulosa que tem como conjuntos de entrada os Grupos 01 a 05 e um sistema de regras. Tanto os conjuntos dos antecedentes quanto o conjunto do conseqüente (INQA) foram criados por funções de pertinência trapezoidais e triangulares (Tabela 08) (Figura 05), tendo sido suas fronteiras delimitadas pelos padrões de qualidade do IQA da CETESB (Tabela 07). Por exemplo, foi pressuposto que a fronteira que separa um índice entre Bom e Ótimo assumisse 50\% de pertinência, tanto no conjunto nebuloso Ótimo quanto no Bom, e assim por diante. Esta metodologia demonstra assim, a inexistência de fronteira rígida entre as classes.

Tabela 07 - Fronteiras das classes do

\begin{tabular}{cl}
\multicolumn{2}{c}{ IQA da CETESB } \\
\hline IQA $<=19$ & - Péssimo \\
$19<$ IQA $<=36$ & - Ruim \\
$36<$ IQA $<=51$ & - Médio \\
$51<$ IQA $<=79$ & - Bom \\
$79<$ IQA $<=100$ & - Ótimo \\
\hline
\end{tabular}

Tabela 08 - Conjuntos nebulosos dos antecedentes e conseqüente da inferência IN06

Gr 01, 02, 03, 04, 05 e INQA

\begin{tabular}{lcccc}
\multicolumn{5}{c}{$0-100$} \\
\hline & $\mathrm{a}$ & $\mathrm{b}$ & $\mathrm{c}$ & $\mathrm{d}$ \\
Ótimo & 65 & 90 & 100 & 100 \\
Bom & 44 & 65 & 90 & \\
Médio & 28 & 44 & 65 & \\
Ruim & 0 & 28 & 44 & \\
Péssimo & 0 & 0 & 9 & 28 \\
\hline
\end{tabular}

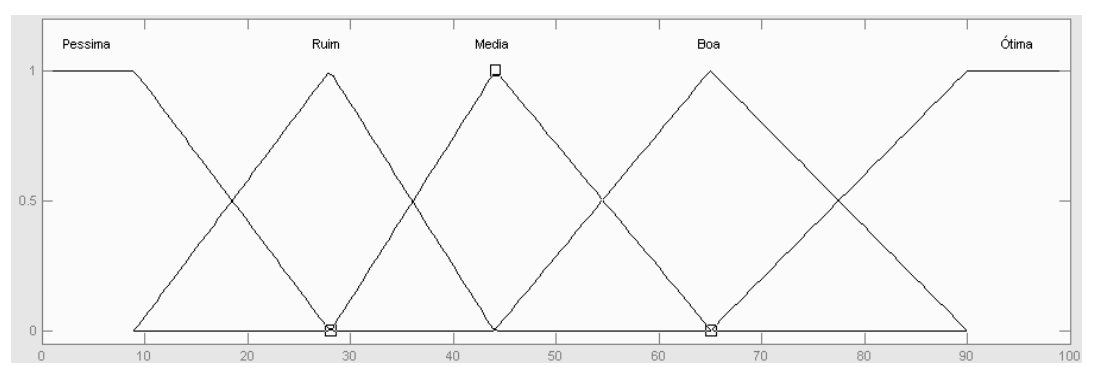

Figura 05 - Gráfico das funções dos conjuntos nebulosos.

Para o sistema de inferência nebulosa que tem como saída o INQA foram criadas 3125 regras que seguiram uma lógica, conforme exemplificado a seguir:

\section{Regra 01:}

Se Gr01 é Ótimo e Gr02 é Ótimo e Gr03 é Ótimo e Gr04 é Ótimo e Gr05 é Ótimo então INQA é Ótimo.

$\cdots$

Regra 830:

Se Gr01 é Bom e Gr02 é Bom e Gr03 é Ruim e Gr04 é Ótimo e Gr05 é Péssimo então INQA é Bom.

$\cdots$

Regra 1214:

Se Gr01 é Bom e Gr02 é Péssimo e Gr03 é Ruim e Gr04 é Médio e Gr05 é Ruim então INQA é Ruim.

Regra 2445:

ENGEVISTA, v. 10, n. 2, p. 106-125 dezembro 2008
Se Gr01 é Ruim e Gr02 é Péssimo e Gr03 é Médio e Gr04 é Ruim e Gr05 é péssimo então INQA é Péssimo.

...

Regra 3125:

Se Gr01 é Péssimo e Gr02 é Péssimo e Gr03 é Péssimo e Gr04 é Péssimo e Gr05 é Péssimo então INQA é Péssimo.

Toda metodologia computacional foi desenvolvida com auxílio do "fuzzy logic toolbox” do pacote MATLAB ${ }^{\circledR}$ (2006).

\section{RESULTADOS E DISCUSSÃO}

Para o desenvolvimento deste estudo foram considerados os resultados das análises dos parâmetros já citados dos 4 pontos da rede de monitoramento da CETESB no rio Pardo, UGRHI 04 do 
Estado de São Paulo, referentes aos anos de 2004 a 2006 (Cetesb, 2004; Cetesb 2005; Cetesb 2006).

O IQA usado pela CETESB não foi calculado, e sim transcrito dos Relatórios de Qualidade das Águas Interiores do Estado de São Paulo (CETESB, 2004, 2005 e 2006). Foram calculados os $\mathrm{IQA}_{\text {sub }}$ (Conesa com $\mathrm{k}=0,75$ para uma

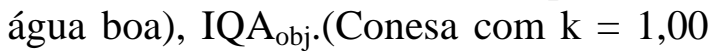
para uma água ótima), IQA conforme descrito por Pesce e Wunderlin (2000) e o IQA conforme Silva e Jardim (2006). O INQA obtido através da metodologia descrita neste estudo também foi calculado e comparado aos outros índices para efeitos de validação da metodologia.

As Figuras 06 - 17 mostram o resultado dos cálculos dos índices citados ao longo dos 4 pontos de amostragem em 3 anos consecutivos. Percebemos através de uma análise visual dos gráficos que os

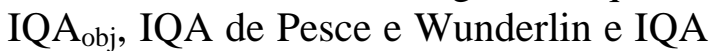
de Silva e Jardim destoam significativamente dos IQA's da CETESB, IQA $A_{\text {sub }}$ e INQA. Estes índices tendem a relatar uma condição mais otimista da condição da água do rio monitorado.

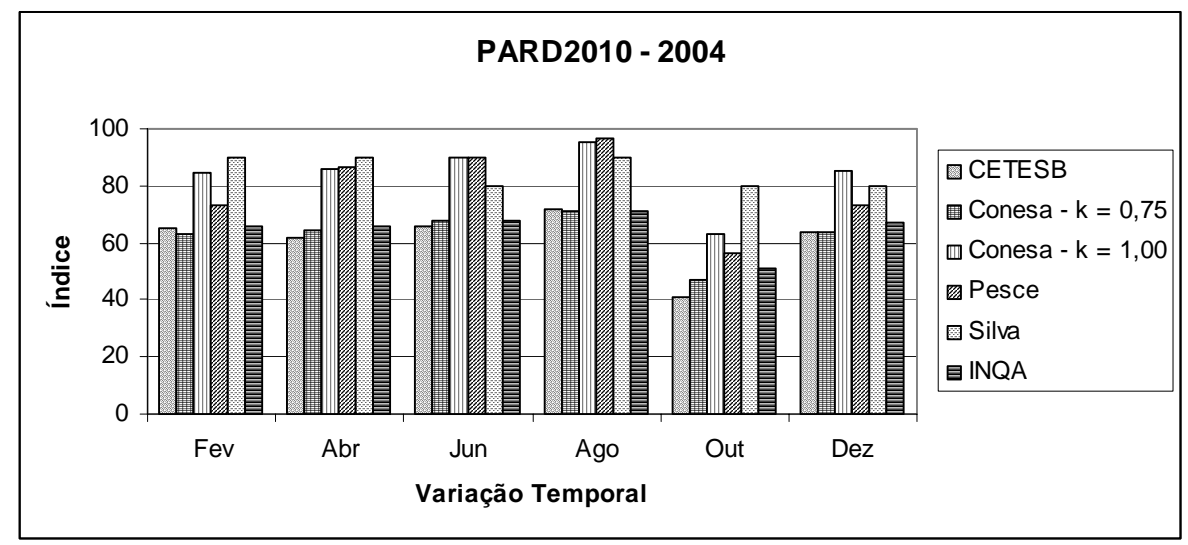

Figura 06 - Comparativo dos Índices - PARD2010, Ano 2004.

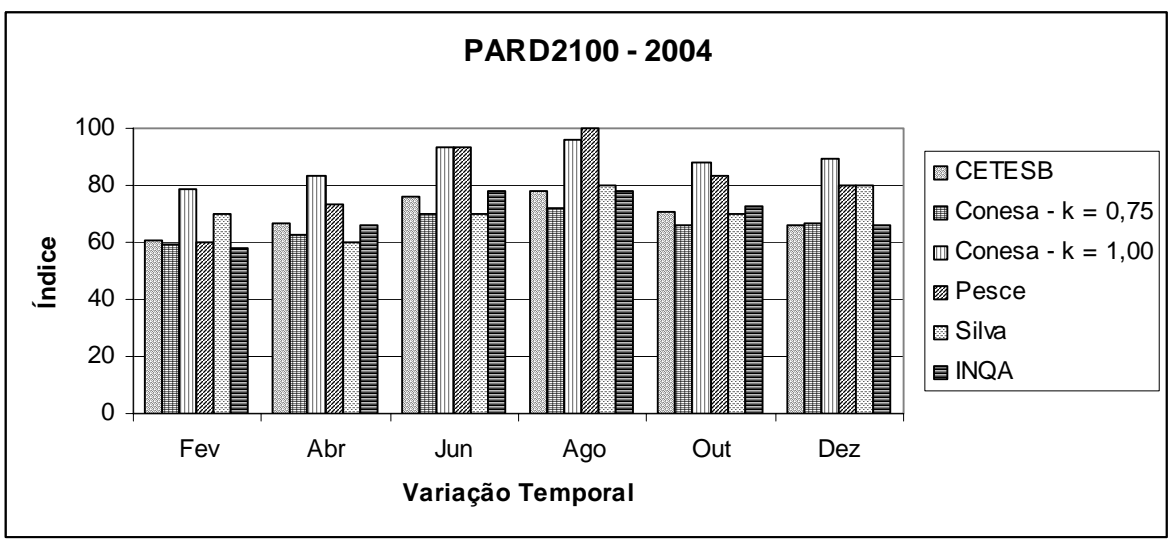

Figura 07 - Comparativo dos Índices - PARD2100, Ano 2004.

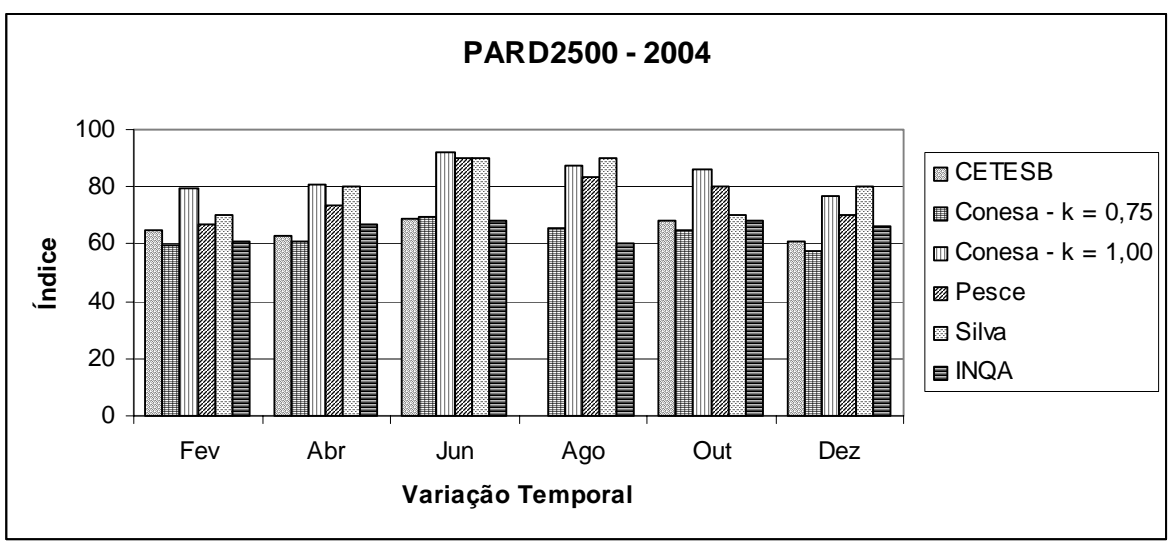

Figura 08 - Comparativo dos Índices - PARD2500, Ano 2004.

ENGEVISTA, v. 10, n. 2, p. 106-125 dezembro 2008 


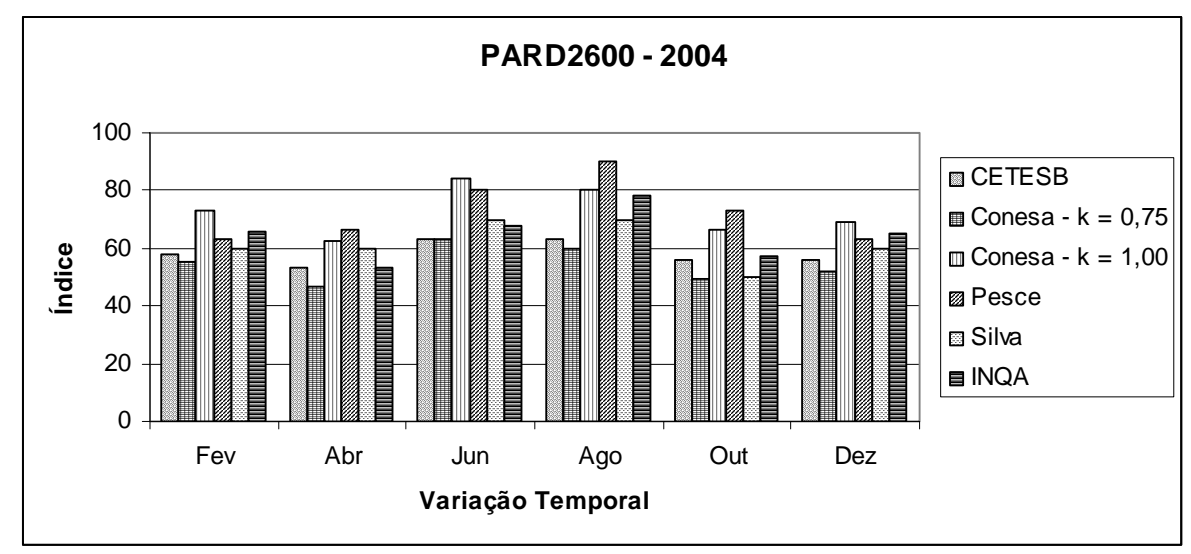

Figura 09 - Comparativo dos Índices - PARD2600, Ano 2004.

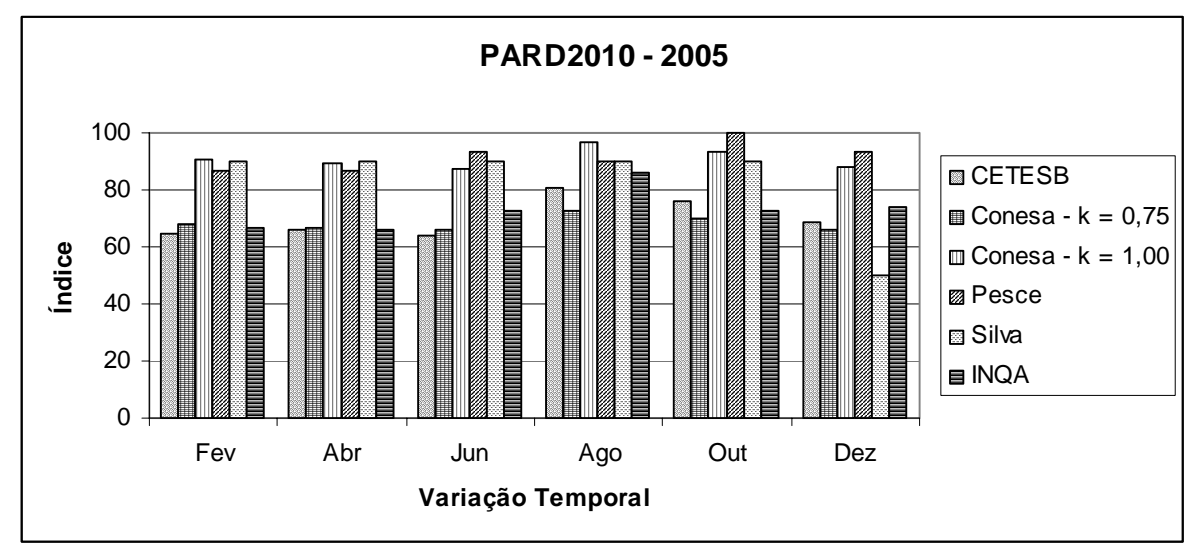

Figura 10 - Comparativo dos Índices - PARD2010, Ano 2005.

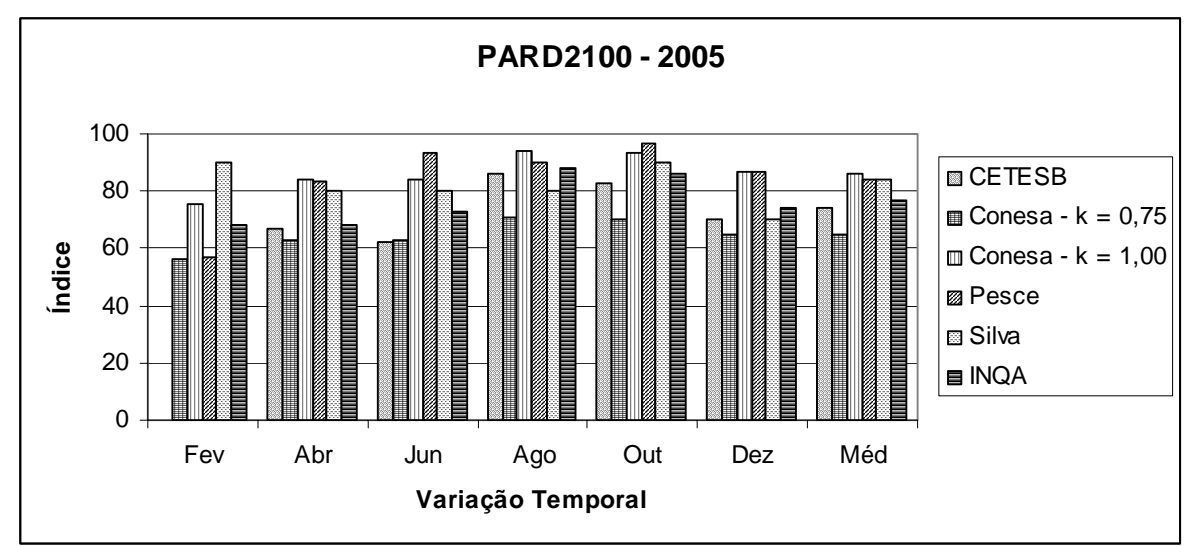

Figura 11 - Comparativo dos Índices - PARD2100, Ano 2005.

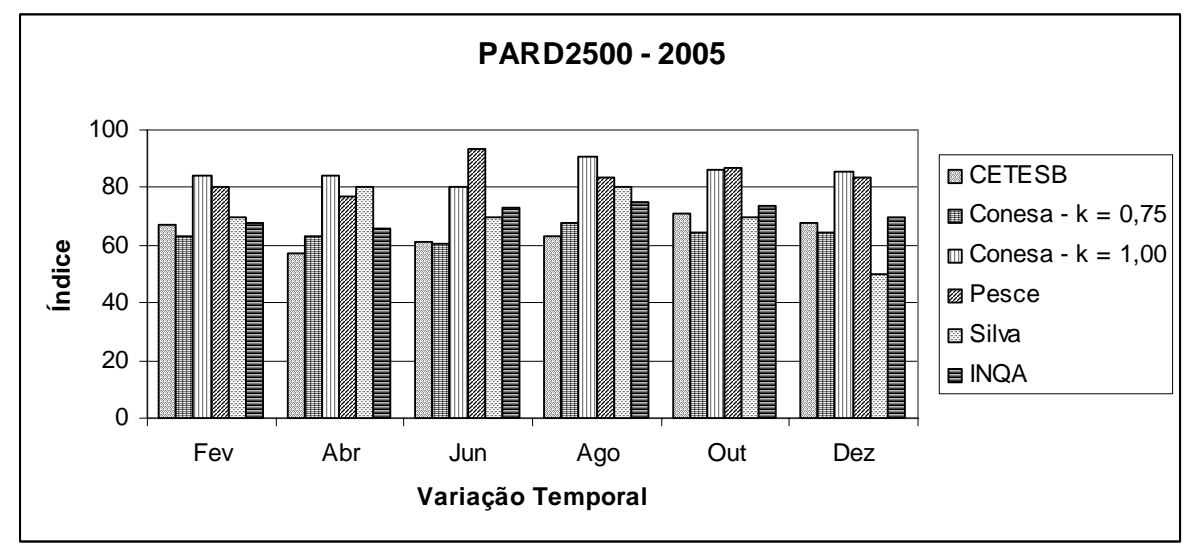

Figura 12 - Comparativo dos Índices - PARD2500, Ano 2005. 


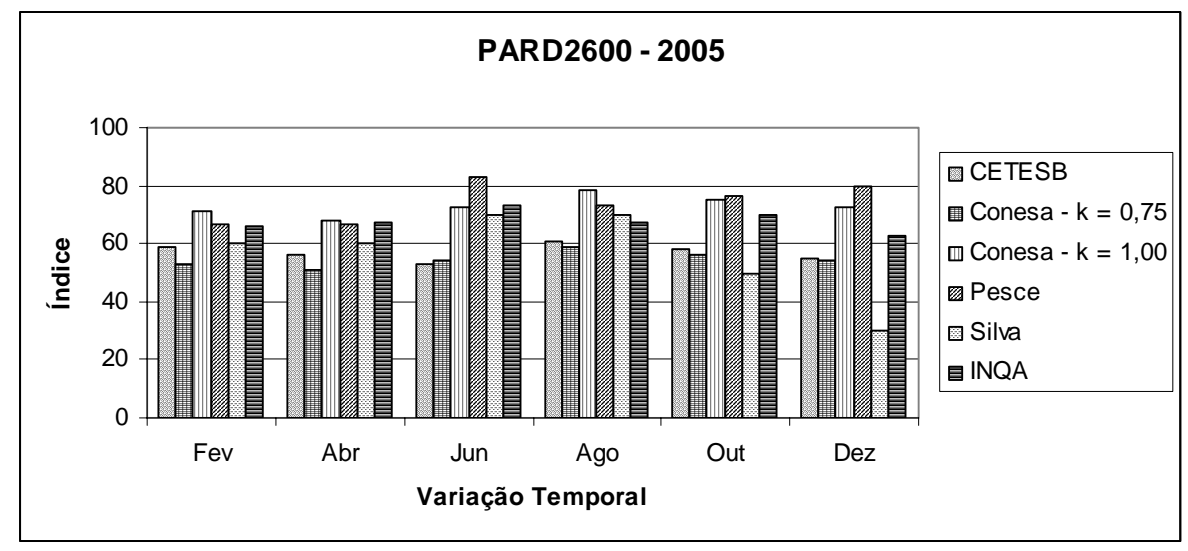

Figura 13 - Comparativo dos Índices - PARD2600, Ano 2005.

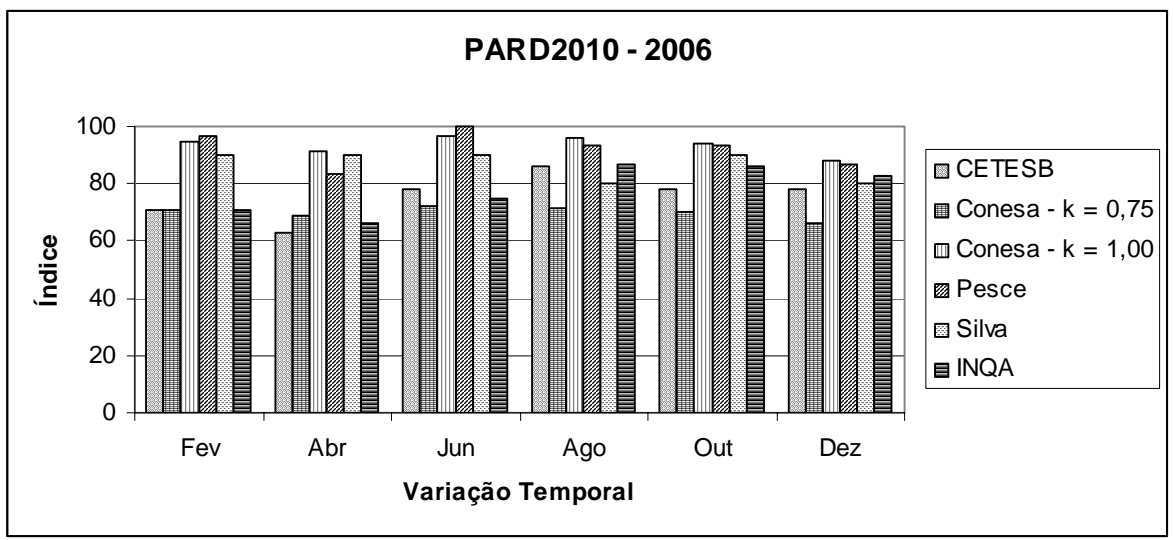

Figura 14 - Comparativo dos Índices - PARD2010, Ano 2006.

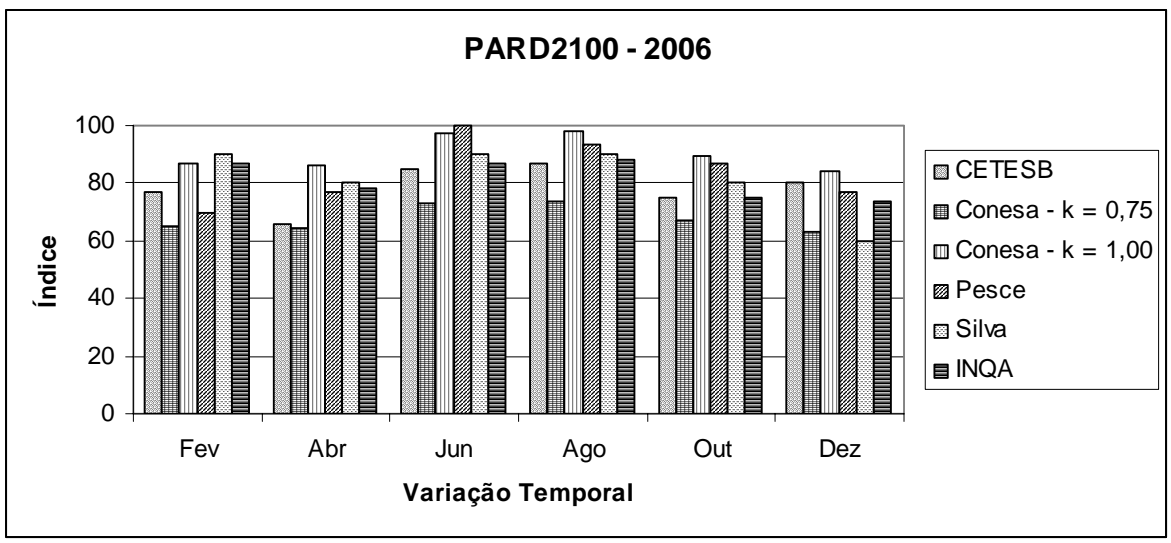

Figura 15 - Comparativo dos Índices - PARD2100, Ano 2006.

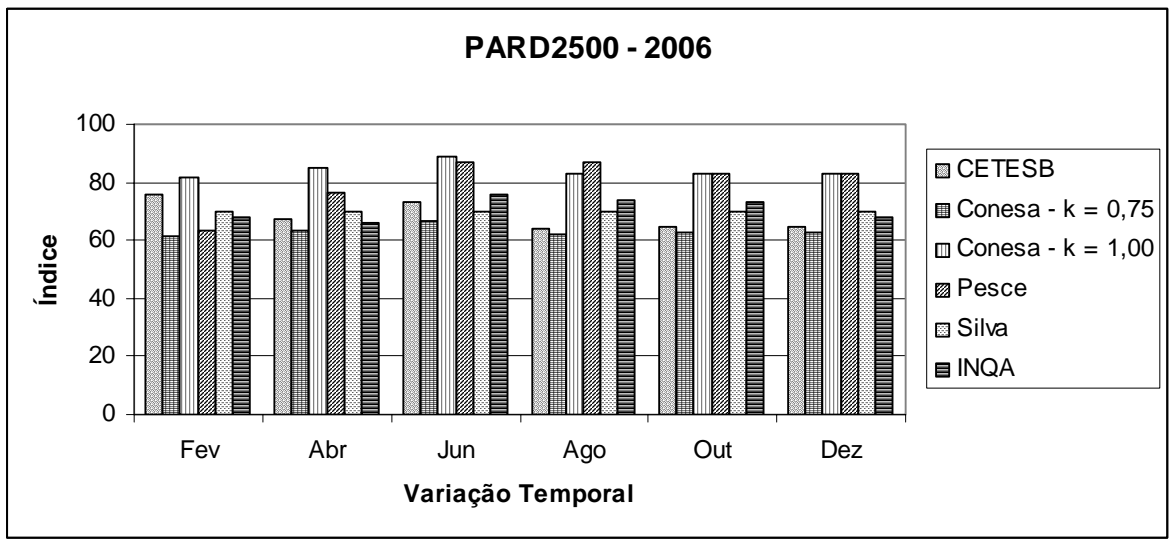

Figura 16 - Comparativo dos Índices - PARD2500, Ano 2006. 


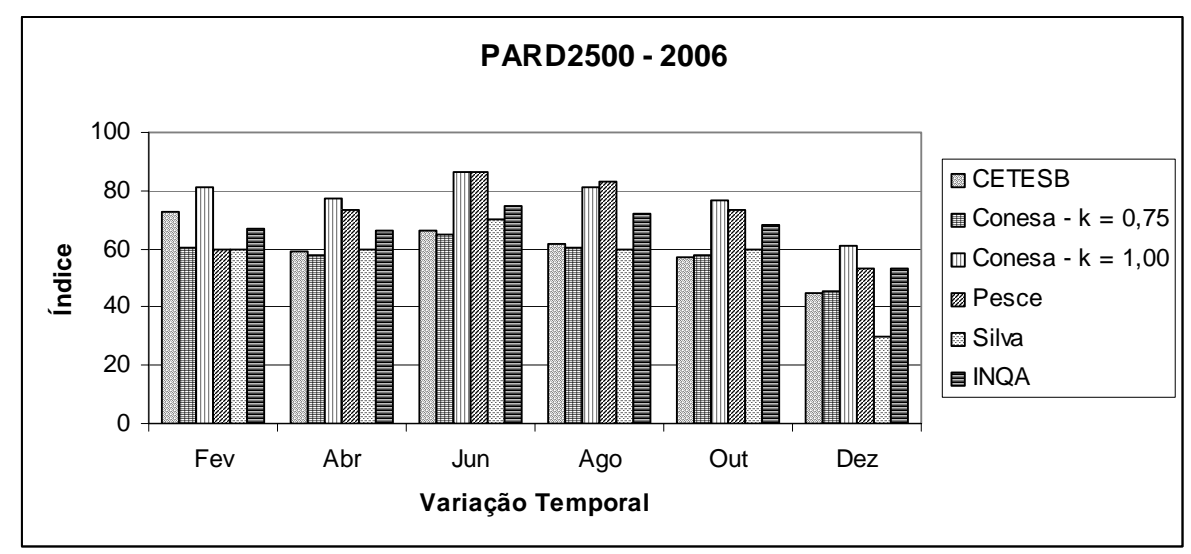

Figura 17 - Comparativo dos Índices - PARD2600, Ano 2006.

A Figura 18 mostra como a média anual de cada índice se comporta em cada um dos pontos de monitoramento. Os índices CETESB, Conesa $(\mathrm{k}=0,75)$ e INQA tendem a uma semelhança entre si. A constante $\mathrm{k}=0,75$ no índice de Conesa mostra a condição mais restritiva e a constante $\mathrm{k}=1,00$, a condição menos restritiva. O INQA tende a acompanhar o IQA da CETESB sendo que, com uma condição menos restritiva para o ponto PARD2600. Na Figura 19 o INQA se mantêm próximos ao IQA da CETESB ao longo dos pontos PARD2010 e PARD2100, mas não acompanha a mesma tendência dos outros dois pontos relatando uma condição menos restritiva da qualidade da água. Novamente o IQA Conesa com constante $\mathrm{k}=0,75$ mostra ser o índice que apresenta a pior qualidade de água. A Figura 20, no ano de 2006, mostra mais uma vez um índice de pior qualidade. Entretanto, todos os outros índices relatam uma qualidade boa à ótima na água em questão. Podemos assim assumir que o fator $\mathrm{k}=0,75$ não corresponde a realidade da água em questão, prevalecendo o resultados dos outros índices. O INQA novamente tende a acompanhar o índice da CETESB com um resultado de índice de qualidade ligeiramente mais alto que o mesmo.

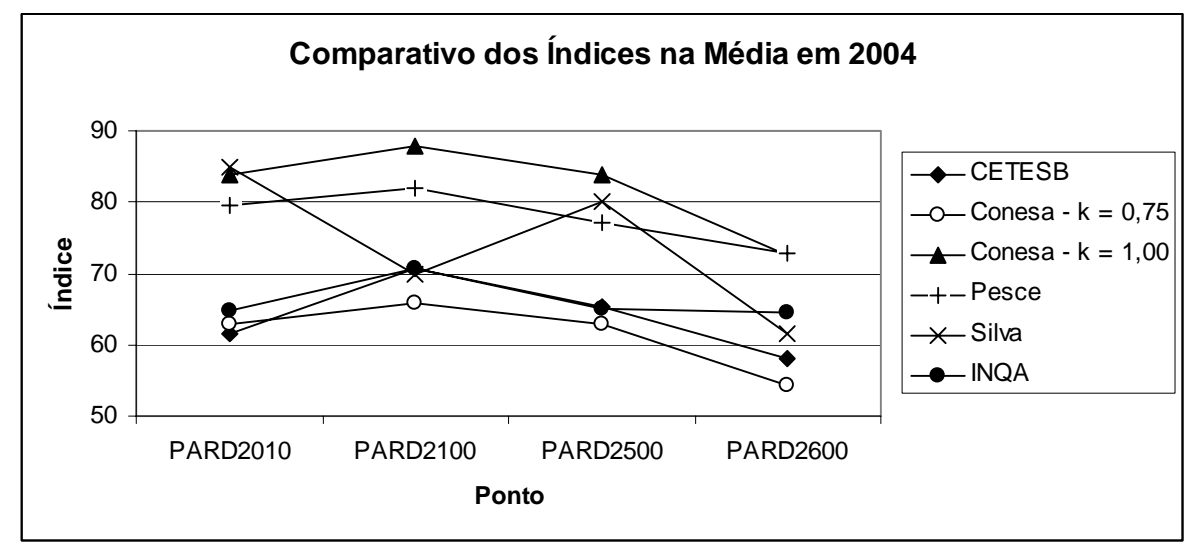

Figura 18 - Comparativo dos Índices na Média, Ano 2004. 


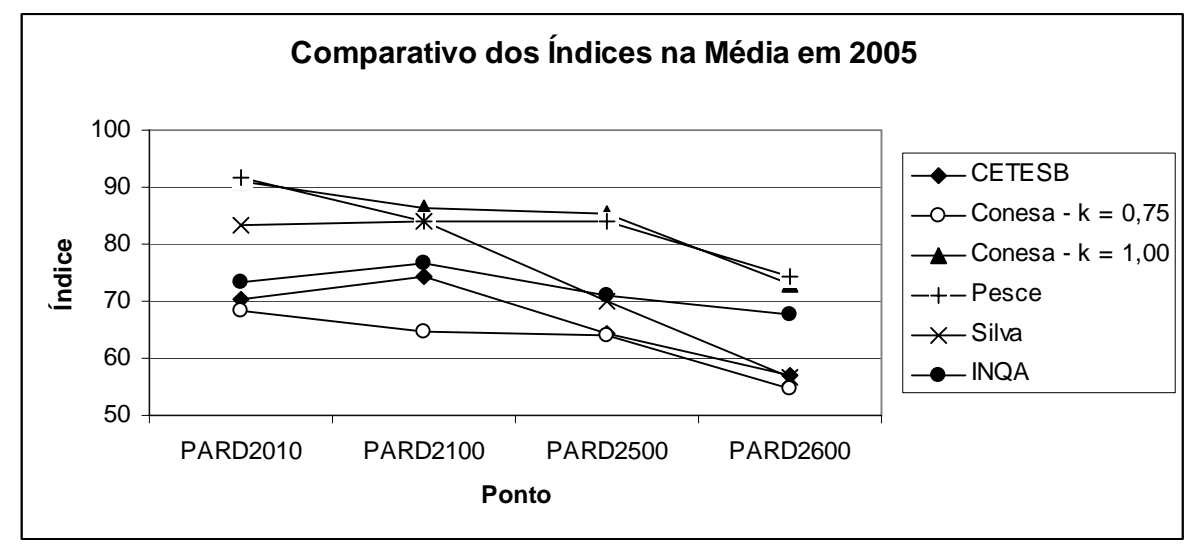

Figura 19 - Comparativo dos Índices na Média, Ano 2005.

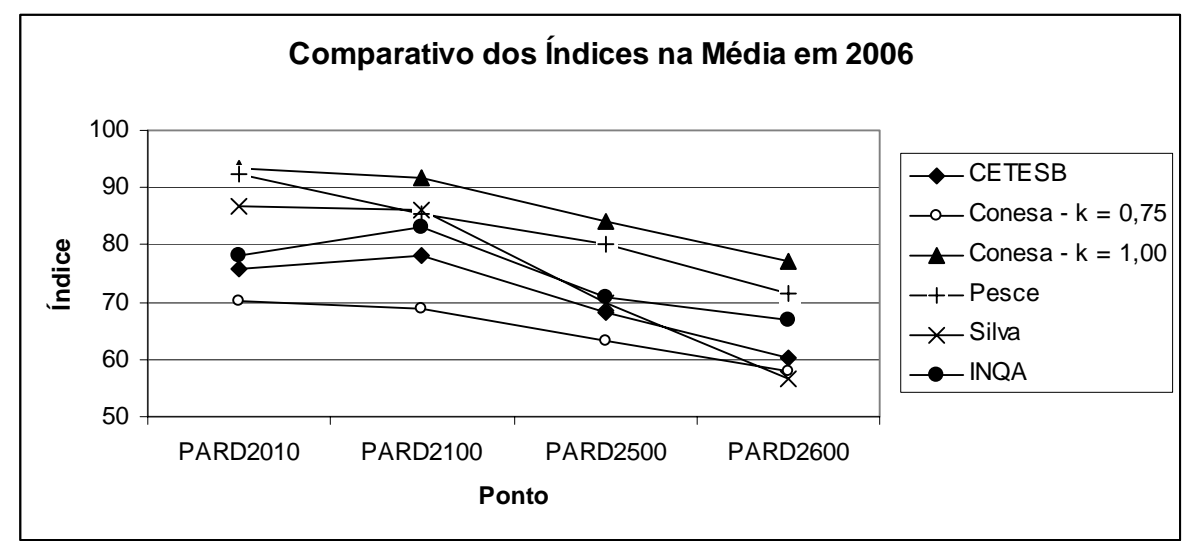

Figura 20 - Comparativo dos Índices na Média, Ano 2006.

Percebemos também que os índices avaliados nos três anos tendem mostrar uma ligeira elevação na qualidade da água do ponto PARD2100 em relação ao ponto PARD2010 com uma seguida queda seqüencial nos dois pontos que sucedem a estes. Podemos concluir que o aporte de águas de escoamento superficial e lançamentos de esgotos após o ponto PARD2100 contribuem para uma diminuição na qualidade no rio Pardo. Também podemos verificar que a qualidade nos pontos PARD2010 e PARD2100 tendem a melhorar ao longo dos anos estudados, demonstrando que medidas para uma melhor conservação deste recurso hídrico já foram tomadas no entorno destes pontos.

Com intenção de validar a metodologia proposta foram traçadas as curvas de correlação de cada um dos índices com o INQA proposto (Figuras 21-25). A melhor correlação entre 0 INQA e os outros índices foi encontrada para o IQA da CETESB com uma correlação de $r=0,82593$ enquanto a pior correlação foi com o índice de Silva e Jardim $\quad(\mathrm{r}=0,45269)$. 


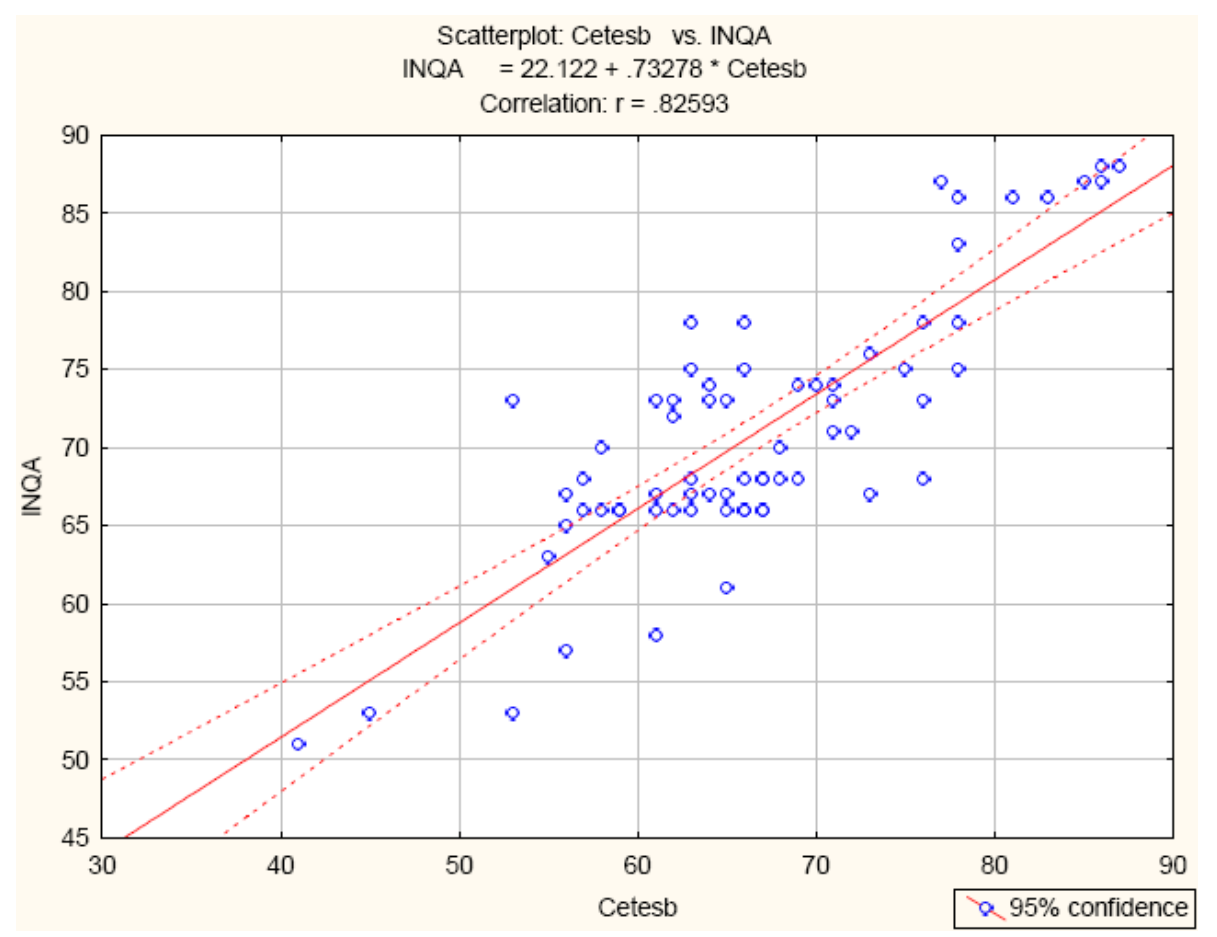

Figura 21 - Correlação INQA x IQA CETESB

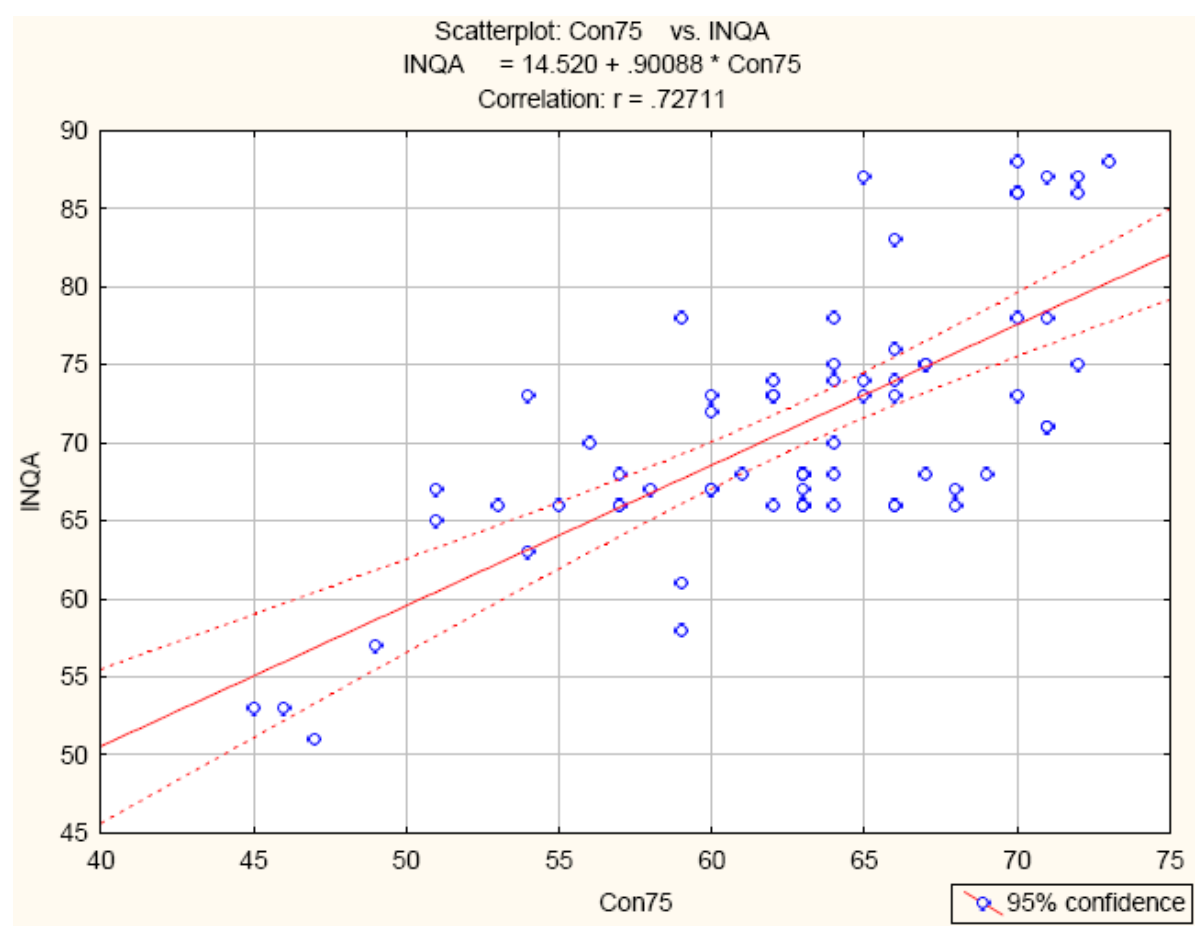

Figura 22 - Correlação INQA x IQA SUB $_{\text {su }}$ 


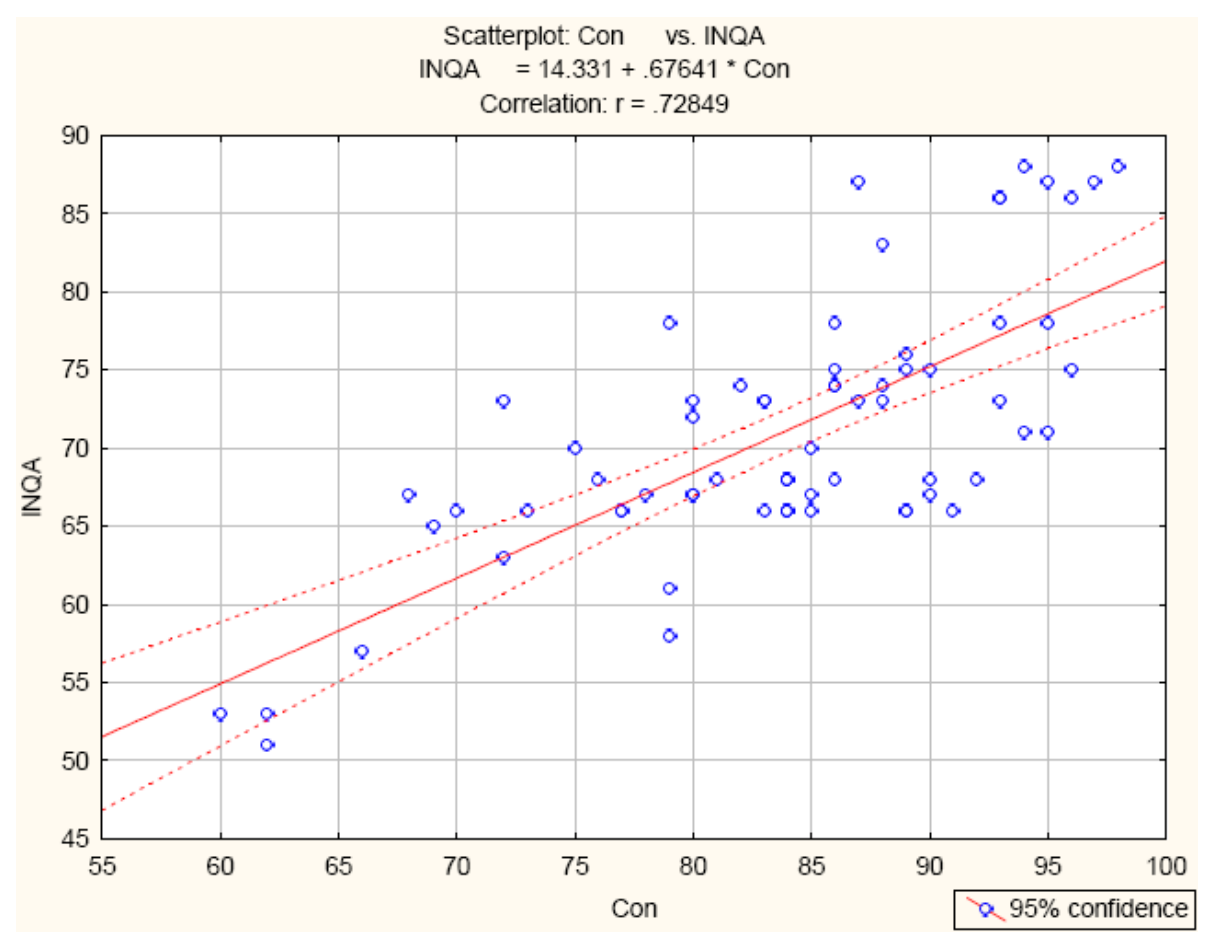

Figura 23 - Correlação INQA x IQA

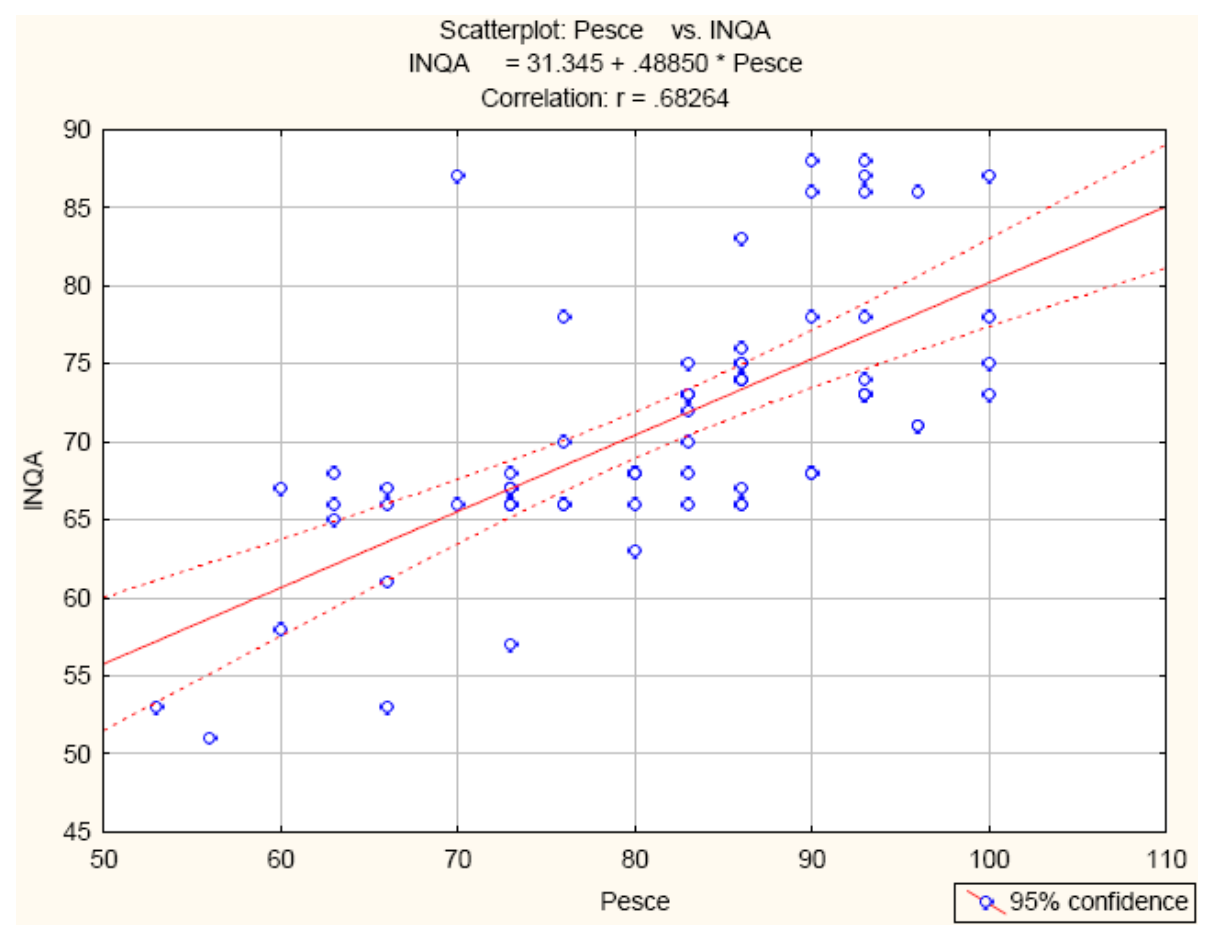

Figura 24 - Correlação INQA x IQA Pesce e Wunderlin 


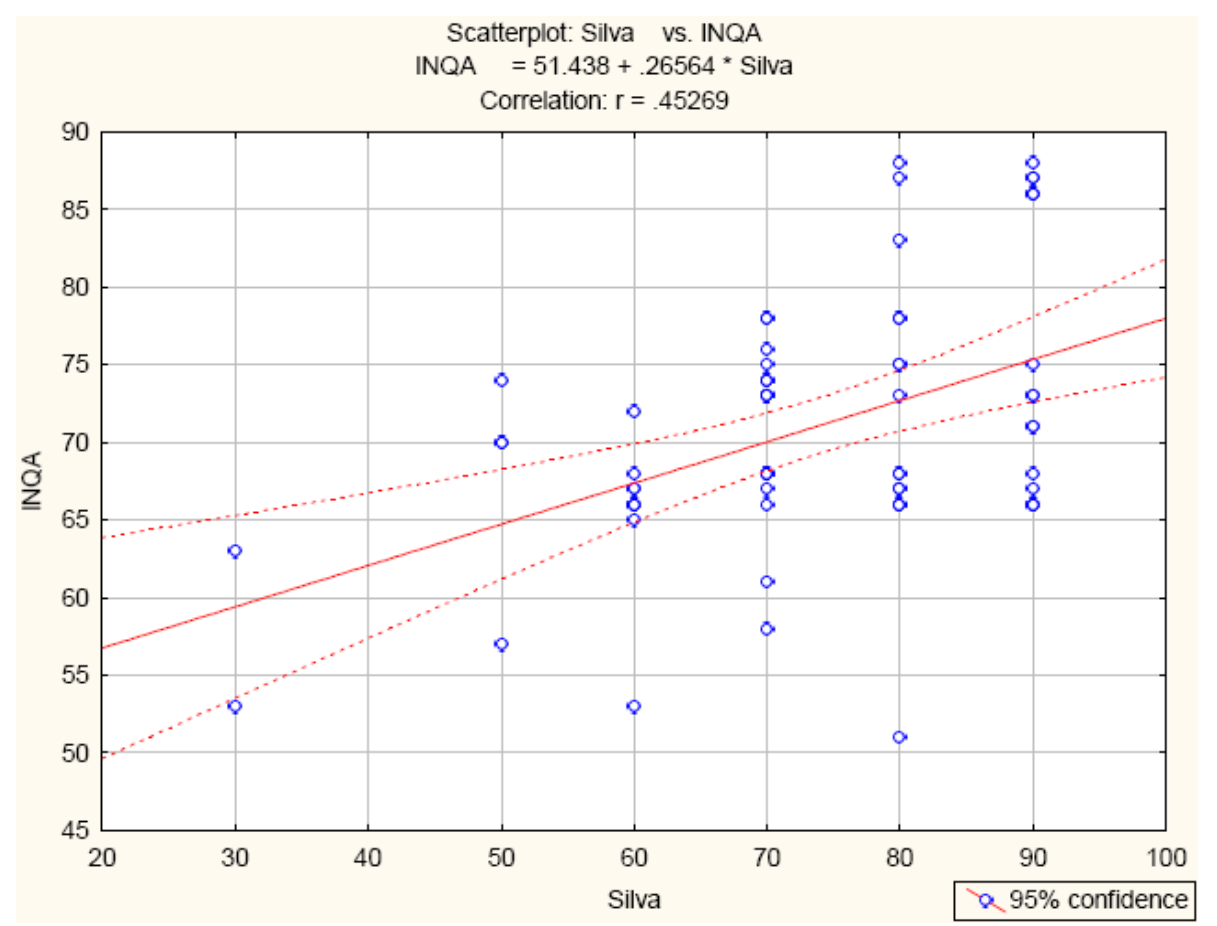

Figura 25 - Correlação INQA x IQA Silva e Jardim

A Figura 26 mostra um gráfico de "Box \& Whiskers" para os índices ao longo dos 3 anos estudados. O ponto central mostra a média. O quadrado maior a média com o desvio padrão para cima e para baixo e a linha a média \pm 1,96 vezes o desvio padrão. Comprovamos através deste que a proposta de se utilizar a metodologia com o uso da lógica nebulosa para desenvolver um Índice de Qualidade das Águas foi realizada com sucesso, uma vez que o gráfico mostra o INQA como um índice compatível com os outros calculados pelas diversas metodologias propostas na literatura.

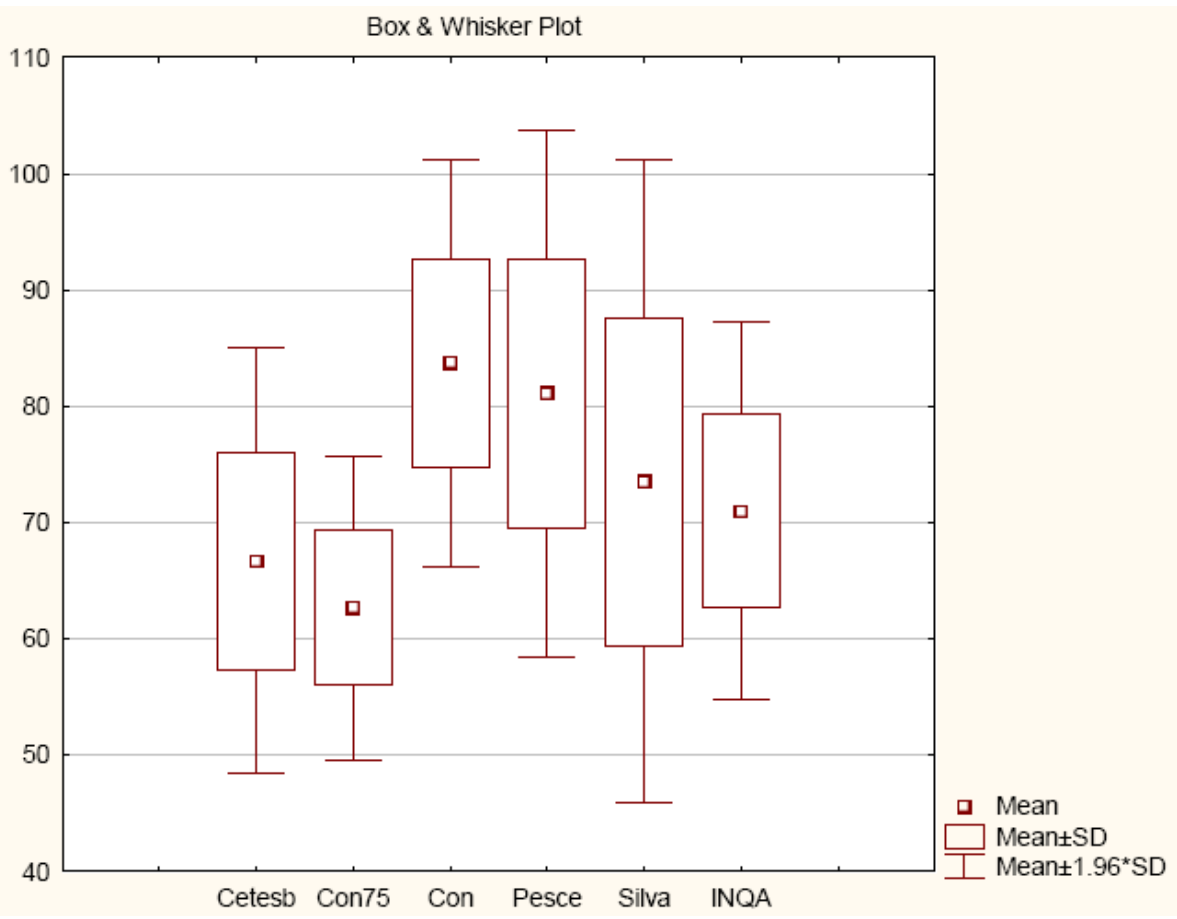

Figura 26 - Gráfico de “Box \& Whiskers”. 


\section{CONCLUSÕES}

Foi desenvolvida, aplicada e discutida uma nova metodologia de indexação de qualidade de rios através da técnica do sistema de inferência nebulosa. Um novo índice, denominado de Índice Nebuloso de Qualidade das Águas INQA foi desenvolvido e discutido. Criou-se este índice para suprir as lacunas existentes no que tange ao monitoramento ambiental, a classificação da qualidade da água e a gestão das unidades de gerenciamento hídricas, quando metodologias convencionais determinísticas tradicionais se mostram imprecisas. As aplicações práticas deste novo índice foram testadas com um estudo de caso realístico no rio Pardo no estado de São Paulo, Brasil. O índice desenvolvido se mostrou confiável e compatível com as outras metodologias tradicionais. Logo, esta metodologia pode ser utilizada como uma ferramenta alternativa no tratamento de dados de qualidade de águas de bacias hidrográficas, no planejamento de estratégias e tomadas de decisões no âmbito da gestão ambiental integrada.

\section{REFERÊNCIAS}

BORDALO A. A., NILSUMRANCHIT W., CHALERMWAT, K. (2001), Water quality and uses of the Bangpakong river. Water Resaerch Vol. 35, 15, p. 36353642

BÁRDOSSY, A., DUCKSTEIN, L Fuzzy rule-based modeling with applications to geophysical, biological and engineering systems. CRC Press, Boca Raton, New York, London, Tokyo, 1995

CHAU, K. (2006). A review on integration of artificail intelligence into water quality modeling. Marine Pollution Bulletin 52, p.726-733.

CALDEIRA, A. M. et al., Inteligência Computacional aplicada a administração, economia e engenharia em Matlab. São Paulo: Thomson Learning, 2007
Companhia de Tecnologia de Saneamento Ambiental (CETESB); Relatório de Qualidade das Águas Interiores do Estado de São Paulo, São Paulo, 2004 a 2006.

CONESA FERNANDES-VITORA V. (1997). In: Methodological Guide for Environmental Impact Evaluation), 3nd ed., p.412. Mundi-Prensa, Madrid, Spain.

CRUZ, A. J. de O. Lógica Nebulosa. Notas de aula, Universidade Federal do Rio de Janeiro, 17 de junho de 2004

CUDE, C.O. (2001). Water quality index: $a$ tool for evaluating water quality management effectiveness, J. Am. Water Resour. Assoc. 37 125-137.

DAHIYA S., SINGH B., GAUR S., GARG V.K., KUSHWAHA H.S., (2007), Analysis of groundwater quality using fuzzy synthetic evaluation. Journal of Hazardous Materials 147 938-946

HORTON, R. K. (1965). Na index number system for rating water quality. Journal of Water Pollution Control Federation 37 (3), p.300-305.

HOUSE, M. A.; ELLIS, J. B., (1987). The development of water quality indexes for operational management. Water Sci. Technol. 19, 145.

ICAGA, Y.; (2007). Fuzzy evaluation of water classification. Ecological Indicators 7, p.710-718

LANDWEHR, J. M.; DEININGER, R. A., (1976). Comparison of several water quality indexes. Journal Water Ppollut. Con. F. 48, p.954-958

LIOU, S.; LO S.; WANG, S. (2004). A generalized water quality index for Taiwan. Environmental Monitoring Assessment 96, p. 35-52.

MATLAB ${ }^{\circledR}$ 7.0; Packaged software for technical computing, Release 14, The Math works, Inc. (2006)

MITCHELL, M.K., STAPP, W.B. Field Manual for Water Quality Monitoring: an Environmental Education Program or Schools, Thomson-Shore Inc., Dexter, Michigan, 1996, p. 277. 
[NSF] National Sanitation Foundation International. (2007). Disponível em: http://www.nsf.org [Acessado em Outubro de 2007].

OCAMPO-DUQUE W., FERRÉHUGUET N., DOMINGO J. L., SCHUHMACHER M., (2006), Assessing water quality in rivers with fuzzy inference systems: A case study. Environment International 32, p. 733742

ONGLEY, E.; (1998). Modernization of water quality programs in developing coutries: issues of relevancy and cost efficiency. Water Quality International Sep/Oct, p. 37-42

PESCE, S. F., WUNDERLIN, D. A.; (2000) Use of water quality indices to verify the impact of Córdoba city (Argentina) on Suquía river Water Research 34, 2915-2926

ROSS, T. J. Fuzzy logic with engineering applications. New York: John Wiley \& Sons. 2004

SAID, A, STEVENS, D, SELKE, G. (2004). An innovative index for evaluating water quality in streams. Environ Manage, 34:406-14.

SDD (1976) Development of a Water Quality Index. Scottish Development Department, Report ARD3, Edinburgh, 35pp.

SILVA, G. S.; JARDIM, W. de F. (2006). Um novo índice de qualidade de águas para proteção de vida aquática aplicado ao rio Atibaia, região de Campinas/Paulínea - SP. Química Nova 29, No. 4, p. 689-694

SILVERT, W. (1997), Ecological impact classification with fuzzy sets. Ecological Modeling 96, p.1-10

SILVERT, W. (2000), Fuzzy indices of environmental conditions. Ecological Modeling 130, p.111-119.

STAMBUK-GILJANOVIC N. (1999), Water quality evaluation by index in Dalmatia, Water Research Vol 33, 16, pp. 3423-3440
YAGER, R. R., FILVEL, D.P, Essentials of Fuzzy Modeling and Control, New York: John Wiley \& Sons, 1994

YEN, J., LANGARI, R. Fuzzy logic: intelligence, control, and information, Prentice-Hall, Inc., 1999

ZADEH, L.A. (1965). Fuzzy Sets, Information and Control n. 8, 338-353 